\title{
Productivity versus product quality: Exploring the limits of autothermal microchannel reactors in methane steam reforming
}

\author{
Georg Liesche ${ }^{\mathrm{a}}$, Kai Sundmacher ${ }^{\mathrm{a}, \mathrm{b}}$ \\ a Max Planck Institute for Dynamics of Complex Technical Systems, Department Process Systems Engineering, Sandtorstr.1, D-39106 Magdeburg, Germany \\ ${ }^{\mathrm{b}}$ Otto-von-Guericke-University Magdeburg, Department Process Systems Engineering, Universittsplatz 2, D-39106 Magdeburg, Germany
}

\section{H I G H L I G H T S}

- Radiation is significant in autothermal channel reactors.

- Radiative heat transfer dominates across the channels for widths above $1 \mathrm{~cm}$.

- Microchannel reactors achieve high product purities and yields due to high conduction.

- Channels with few millimeters width beat microchannels in catalyst productivity.

- Heat transfer performance is comparable for both scenarios.

\section{A R T I C L E I N F O}

\section{Keywords:}

Reactor design

Heat transfer

Radiation

Methane steam reforming

Microreactor
G R A P H I C A L A B S T R A C T

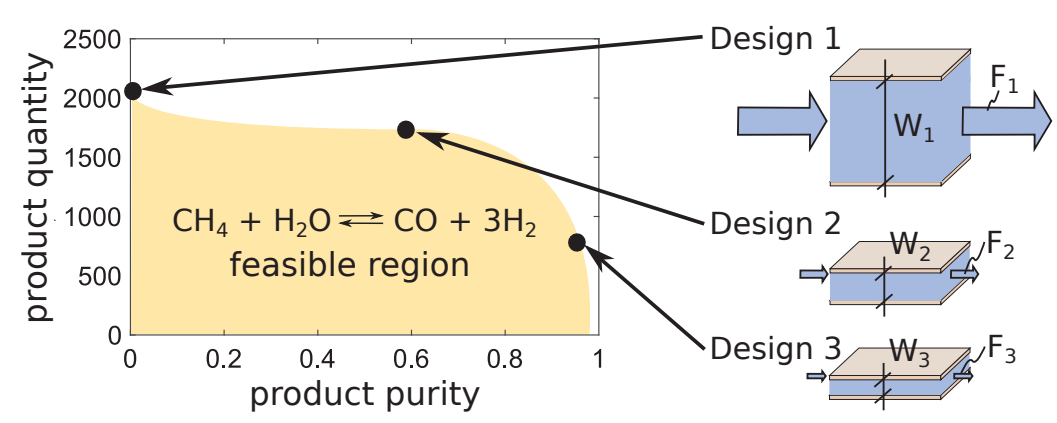

\begin{abstract}
A B S T R A C T
Energy-intensive endothermal gas phase reactions such as methane steam reforming constitute an essential class of chemical processes that provide feedstocks for the chemical industry. Autothermal reactor designs that couple endothermal reforming with exothermal combustion reactions are an effective means of process intensification towards a more sustainable production. Besides a proof of these reactor concepts, however, there is a need for optimization of the reactor design and operating parameters. Using a high-fidelity first-principles reactor model that includes the solution of the radiative transfer equation the optimal design of an autothermal channel reactor is identified emphasizing the heat transfer inside the reforming compartment. A two-step approach is proposed starting with the design of the reforming side followed by the design of the combustion side with two-compartment model. Highest product purity in combination with minimum heat transfer barriers dominated by conduction is achieved with a microchannel reactor with widths up to few millimeters. An increase in catalyst productivity, however, is only achieved with a reactor width of $8 \mathrm{~mm}$ and more where radiative heat transfer becomes significant. A technological optimal design is thus subject to the plant and economical constraints at a specific site and therefore balancing of purity, energy efficiency and productivity is required in any given scenario.
\end{abstract}

\section{Introduction}

With an annual resource consumption of 1.7 earths, the human population is using more resources than nature can regenerate within a year [1]. Besides other consequences, a strong reduction of the ecological footprint of the chemical industry is required which is only achievable by process intensification and retrofitting on the short term
$[2,3]$. Steam reforming of methane (MSR) is a key technology of the chemical industry both for synthesis gas production - $\mathrm{CO}$ and $\mathrm{H}_{2}-$ and also as a cost-effective means of synthesis of pure $\mathrm{H}_{2}$ [4,5]. Drawback of MSR is its high energy consumption which is illustrated by the two principle endothermic reactions Eq. (a) and Eq. (b). The water-gas-shift reaction (Eq. (c)) constitutes the third most important reaction in a MSR reactor. 


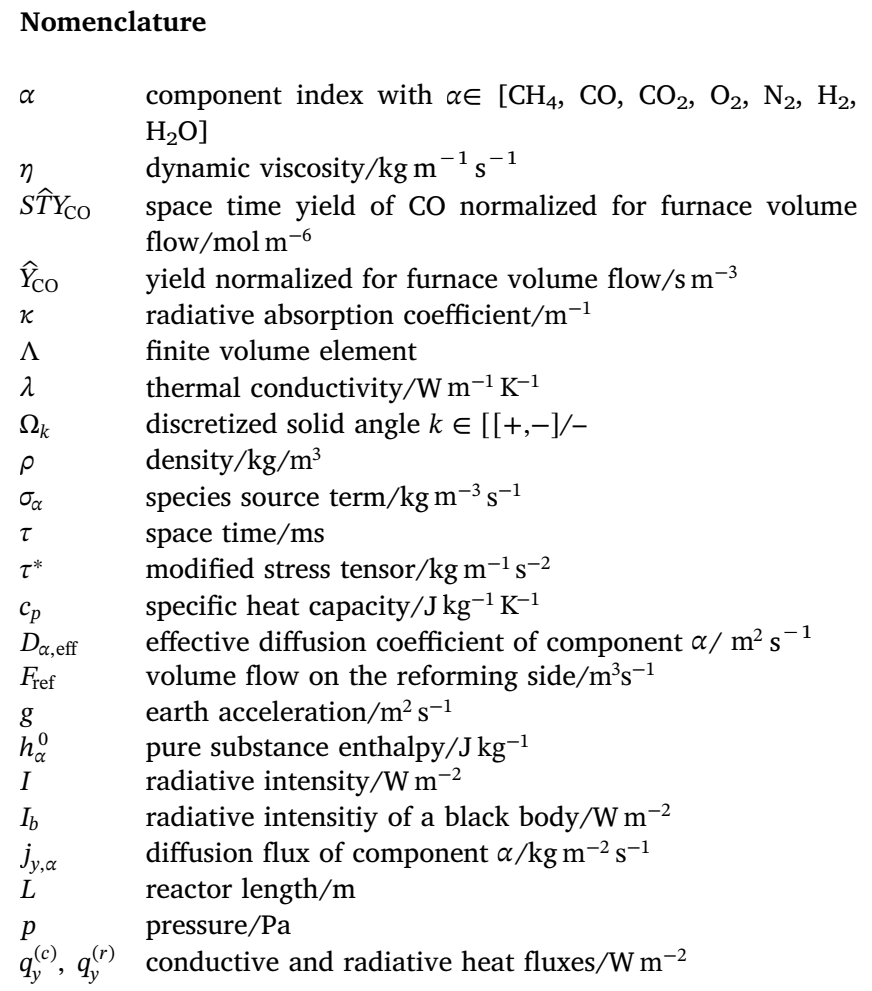

$s$

$S / C$

$S_{\mathrm{CO}}$

SN

$S T Y_{i}$

$T$

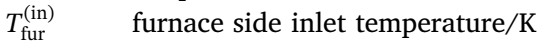

$T_{w} \quad$ wall temperature/K

$V_{\Lambda} \quad$ volume of finite volume element $\Lambda / \mathrm{m}^{3}$

$v_{y}, v_{z} \quad$ velocity in $y, z$ directions $/ \mathrm{m} / \mathrm{s}$

$w_{\alpha} \quad$ mass fraction of component $\alpha /-$

$W_{\text {fur }} \quad$ width of furnace side/m

$W_{\text {ref }} \quad$ width of reforming side $/ \mathrm{m}$

$X_{\mathrm{CH}_{4}}$ conversion of $\mathrm{CH}_{4}$ as defined in Eq. (14a)/\%

$x_{\mathrm{N}_{2}} \quad$ mole fraction of $\mathrm{N}_{2}$

$y \quad$ width coordinate of reactor model $/ \mathrm{m}$

$Y_{\mathrm{CO}} \quad$ yield of $\mathrm{CO} / \%$

$z \quad$ length coordinate of reactor model $/ \mathrm{m}$

BLF boundary layer flow

CFD computational fluid dynamics

FV finite volumes

MSR methane steam reforming

Pl Planck number, conduction-to-radiation ratio

RTE radiative transfer equation
$\mathrm{CH}_{4}+\mathrm{H}_{2} \mathrm{O} \leftrightharpoons 3 \mathrm{H}_{2}+\mathrm{CO} \quad \Delta_{\mathrm{R}} h^{\ominus}=206.1 \mathrm{~kJ} \mathrm{~mol}^{-1}$

$\mathrm{CH}_{4}+2 \mathrm{H}_{2} \mathrm{O} \leftrightharpoons 4 \mathrm{H}_{2}+\mathrm{CO}_{2} \quad \Delta_{\mathrm{R}} h^{\ominus}=165.0 \mathrm{~kJ} \mathrm{~mol}^{-1}$

$\mathrm{CO}+\mathrm{H}_{2} \mathrm{O} \leftrightharpoons \mathrm{H}_{2}+\mathrm{CO}_{2} \quad \Delta_{\mathrm{R}} h^{\ominus}=-41.2 \mathrm{~kJ} \mathrm{~mol}^{-1}$

Conventional reactor designs are tube bundle reactors. The endothermic reactions take place inside tubes that are filled with catalyst pellets that are surrounded by a furnace chamber which provides the heat of reaction $[6,7]$. Besides process intensification efforts on the entire plant scale comprising sophisticated coupling of the reformer to other process units, many works exist on the process intensification of the reactor itself $[8,9]$ with both simplified one-dimensional and high fidelity computational fluid dynamics (CFD) models [10-13]. On a single tube scale, modeling studies have been done on the optimization of operating parameters, thermodynamic limits of the reactor as well as optimization of heat flux profiles along a reactor [14-16].

Additionally, several approaches towards alternative reactor designs exist including solar reactors [17], membrane reactors [18] and autothermal reformer designs that combine exo- and endothermic reactions in a single compartment $[19,5]$. Autothermal microreactors have been reported with experimental studies that reduce transport limitations between exo- and endothermic reaction compartments while maintaining the advantage of spatial separation of reaction products and thus high product purities [20-22]. In order to enhance mixing, Fazeli et al. suggest a zig-zag design and Huang et al. suggest a fractal reactor design exploiting the advantages of static mixing with increasing catalyst amounts towards the reactor outlet [23,24].

Microreactors are often referred to as benchmark reactors because small channels and thus high area-to-volume ratios minimize transport barriers and increase the reactor performance [25]. Some authors also investigated the combination of microreactors and autothermal reforming: Chaniotis et al. studied operation parameters of a monolith and Murmura et al. compared different dosing procedures of $\mathrm{O}_{2}$ along the reactor channel wall but without a flux optimization for the optimal dosing profile that could be obtained e.g. using the elementary process function methodology [26-29]. Coupling exo- and endothermal reactions in a single compartment without spatial separation reduces the heat transfer limitations further but leads to more byproducts and higher purification efforts in the downstream processing. Experimental investigations of different channel configurations including e.g. preheating with separated exo- and endothermal compartments have been performed by Wanat et al. for ethanol reforming and by Venkataraman et al. for MSR [30,31]. Ricca et al. did experiments with silicium carbide as a carrier material to reduce the thermal conductivity barrier in a monolith [32]. In addition, surface and volume-based kinetics were compared with experimental data identifying the diffusional limitations in MSR neglecting, however, the discussion of heat transfer limitations $[33,34]$. The biggest challenges in elucidating the detailed heat transfer mechanisms in a quantitative way are the experimental hurdles at the temperatures of interest. Consequently, understanding of the importance of the involved heat transfer modes relies strongly on reactor modeling: Wolf et al. report that radiation is not relevant for their autothermal packed bed reforming reactor [35]. Based on the work by Frauhammer et al. on microchannel reactors, the group of Eigenberger developed a simplified reactor model to control hotspots in the autothermal reactor and compare different autothermal reactor concepts to identify the best operating conditions [36,37]. Mundhwa et al. investigated autothermal microchannel reactors using a CFD code. They report that deposition of catalyst on the channel walls in a segmented instead of a continuous layer on the exothermal catalytic combustion side increases the performance of an autothermal reactor [38]. More CFD studies have been performed for a monolith with channels in cocurrent and crossflow arrangements where a reduction of hotspots was identified for the cocurrent flow but performance was overall similar [39]. The authors use a channel width of $0.7 \mathrm{~mm}$ in their monolith model and a separate group postulates that channel width has no impact at all in their CFD study [40]. On the contrary, Zhai et al. compare channel design and operating parameters in their CFD study claiming that $0.5 \mathrm{~mm}$ is - among the three widths that they investigated - the ideal channel width [41]. Stutz et al. identified an optimal channel diameter of $1.7 \mathrm{~mm}$ for $\mathrm{H}_{2}$ production using a microkinetic reaction model in their study [42]. They observe that the channel performance on the endothermic side drops for widths that are larger than $2.5 \mathrm{~mm}$. 
Based on these contradictory results regarding the optimal microchannel dimensions and the onset of transfer limitations in literature, it is evident that a systematic analysis of heat transfer limitations for the autothermal reactor remains unadressed. Different channel geometries have been proposed without a systematic study of the effects of channel geometries on product purity and space time yields. The objective of this contribution is therefore to address these questions with a highfidelity modeling approach emphasizing the importance of an adequate model of all modes of heat transfer - conduction, convection and radiation. The emphasis of this contribution is the design of the reforming side with respect to product purity, heat transfer efficiency as well as catalyst productivity. In the following sections, the modeling approach, the reactor model and solution strategy are explained followed by the results section of the reactor design study which is structured in two parts: a first step serves as an identification of the optimal design and operating parameters of the endothermal reforming side under idealized conditions assuming a constant wall boundary temperature. The feasibility of the so obtained best results are investigated subsequently with a coupled model of the endothermic reforming and the exothermic furnace side.

\section{Methods}

Generally, the depth-versus-width ratio of channel and microchannel reactors is well above one justifying the use of a two-dimensional reactor model - with a length coordinate $z$ and a width coordinate $y$ - and neglecting the effect of depth. The modeling domain for the reactor design problem is illustrated schematically on the left in Fig. 1. Instead of modeling a stack of channels as shown on the right, two characteristic compartments - for the reforming and for the furnace side - are selected and analyzed. Symmetry is exploited for the reforming side whereas the furnace outer wall is considered adiabatic. Three key design parameters are identified for the reactor design: stack length $(L)$ as well as the width of reforming and furnace side $\left(W_{\text {ref }}\right.$, and $W_{\text {fur }}$ ). The catalyst thickness is maintained constant at $100 \mu \mathrm{m}$ for all simulations for two reasons: firstly it enables a direct comparison of catalyst productivity of all scenarios and secondly, coating thickness seems not to affect catalyst productivity per unit catalyst weight [40]. The wall of support material that separates both compartments is set to
$1 \mathrm{~mm}$ to minimize its heat transfer resistance. In addition to that, four operating parameters are essential for the reactor performance: reactant volume flow $F_{\text {ref }}$ and composition which is described by the steam-tocarbon ratio of the feed $S / C:=n_{\mathrm{H}_{2} \mathrm{O}}(z=0) / n_{\mathrm{CH}_{4}}(z=0)$ as well as the furnace volume flow $F_{\text {fur }}$ and furnace inlet temperature $T_{\text {fur }}^{\text {(in) }}$ $:=T_{\text {fur }}(z=0)$. The furnace inlet temperature is directly linked to the fuel to air ratio of the exothermic combustion. Ambient pressure and preheated feed condition $(900 \mathrm{~K})$ are taken from literature to enable a comparison of the results [39-42].

In order to identify the optimal design and operation, a two-step approach is applied: In a first step, the reforming side of the reactor is decoupled from the autothermal system and analyzed separately using a constant wall temperature $T_{w}$ as boundary condition. Width $W_{\text {ref }}$ and feed volume flow $F_{\text {ref }}$ are varied. Variation of width results in constant space times $\tau:=V_{\text {ref }} / F_{\text {ref }}(z=0)$. Once the optimal parameters of the reforming side are identified, the coupled reforming-furnace model is considered in order analyze the feasibility of the reforming designs and to find the best furnace side parameters: $W_{\text {fur }}, F_{\text {fur }}$ and $T_{\text {fur }}^{\text {(in) }}$.

\subsection{Reactor model}

\subsubsection{Model assumptions}

Flow in both the reforming and the furnace compartment is dominated by flow in the z-direction and Reynolds numbers are well above one. Gradients in velocity, concentrations of species and temperature, however, are greater in $y$-direction. Therefore, use of a boundary layer model is justified which means that all transport phenomena are considered in cross-flow $(y)$ direction whereas advection dominates transport in the principle flow direction $z$ [43]. The reactor is modeled in steady-state and an ideal gas mixture is applied due to the near-ambient pressure inside the reactor. Momentum balances are solved for laminar and thermally dilatant flow and catalytic chemical reactions are considered at the reforming compartment catalyst surface neglecting gasphase chemical reactions. The furnace side is modeled as a hot flue gas without chemical reactions. Radiative heat transfer is accounted for with the solution of the radiative transfer equation for an absorbing and emitting medium. The gas mixture is modeled assuming multiple grey and non-scattering gases in a grey enclosure. Wall emissivities are assumed constant.

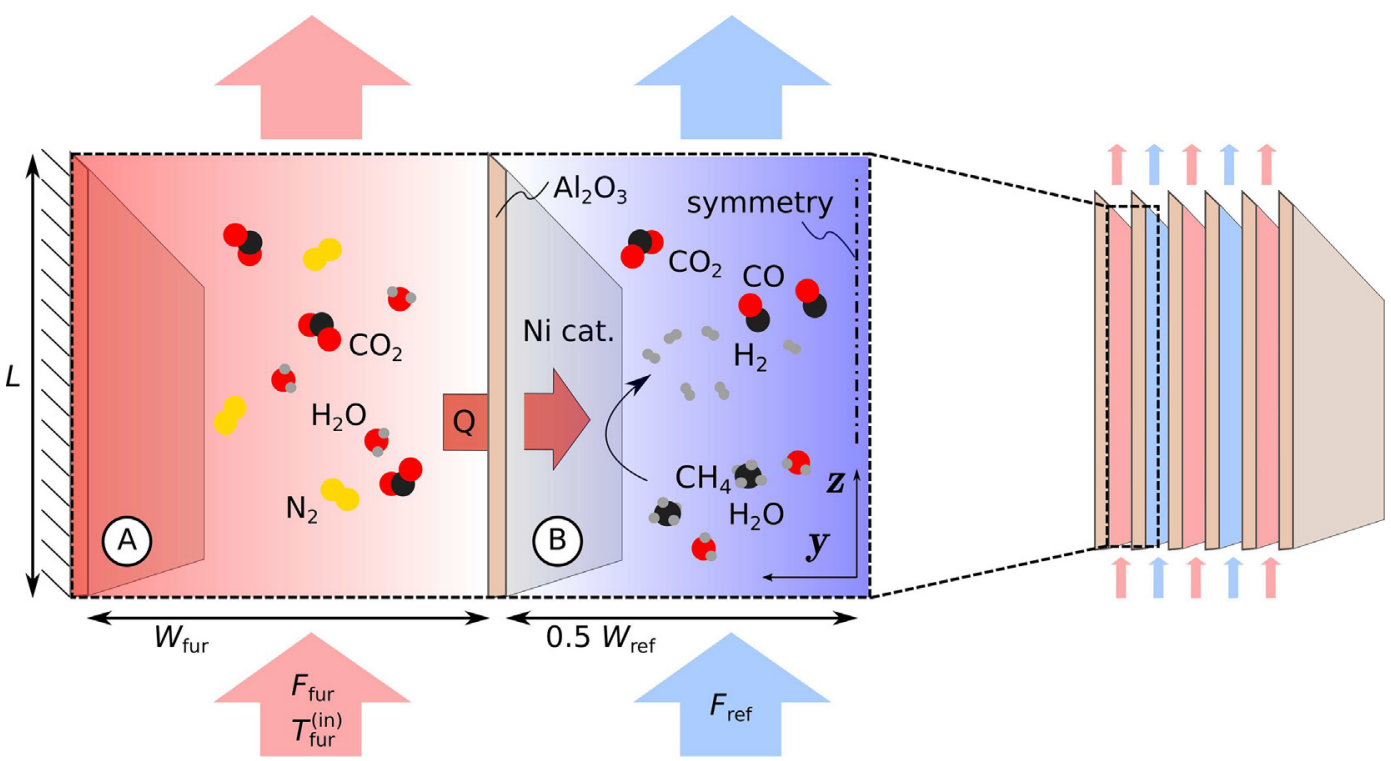

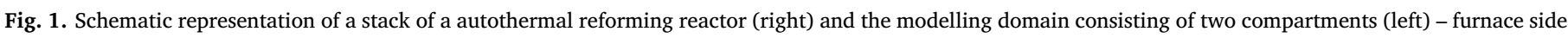

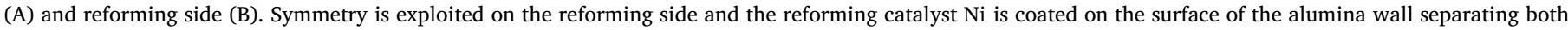

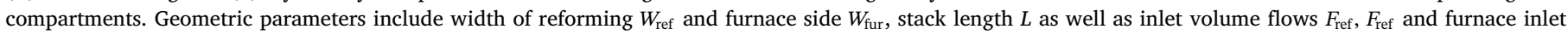

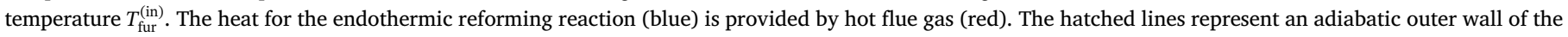
furnace side. (For interpretation of the references to colour in this figure legend, the reader is referred to the web version of this article.) 


\subsubsection{Governing equations}

Based on the assumptions above, a local total mass balance (Eq. (2a)), $n$ species mass balances (Eq. (2a)), - one for each $\alpha \in[1,2, \ldots, n]$, two momentum balances (Eq. (2c), (2d)) an energy balance (Eq. (2e)) are formulated. The equation system Eq. (2) in combination with Eq. (3) apply for both the reforming and the furnace compartment. The radiative transfer equation (RTE, Eq. (2f)) accounts for the changes in radiative intensity. The index $\psi$ represents reforming or furnace side: $\psi \in\{$ ref, fur $\}$.

$\frac{\partial}{\partial z}\left(\rho_{\psi} v_{z, \psi}\right)+\frac{\partial}{\partial y}\left(\rho_{\psi} v_{y, \psi}\right)=0$

$S_{\psi}^{\mathrm{I}}=0$

$\rho_{\psi}\left(v_{z, \psi} \frac{\partial v_{z, \psi}}{\partial z}+v_{y, \psi} \frac{\partial v_{y, \psi}}{\partial y}\right)=-\frac{\partial p_{\psi}}{\partial z}+\frac{\partial \tau_{\psi}^{*}}{\partial y}+\rho_{\psi} g$

$0=\frac{\partial p_{\psi}}{\partial y}$

$\rho_{\psi} c_{p, \psi}\left(v_{z, \psi} \frac{\partial T_{\psi}}{\partial z}+v_{y, \psi} \frac{\partial T_{\psi}}{\partial y}\right)=v_{z, \psi} \frac{\partial p_{\psi}}{\partial z}-\frac{\partial q_{y, \psi}^{(c)}}{\partial y}-\frac{\partial q_{y, \psi}^{(r)}}{\partial y}+S_{\psi}^{\mathrm{II}}+\tau_{\psi}^{*} \frac{\partial v_{z, \psi}}{\partial y}$

$\frac{\mathrm{d} I_{\psi}}{\mathrm{d} s}=-\kappa I_{\psi}(s)+\kappa I_{b, \psi}(s)$

The terms $S_{\psi}^{\mathrm{I}}$ and $S_{\psi}^{\mathrm{II}}$ are defined as follows:

$S_{\psi}^{\mathrm{I}}:=\left\{\begin{array}{cl}\rho_{\text {ref }} v_{z, \text { ref }} \frac{\partial w_{\alpha}}{\partial z}+\rho_{\text {ref }} v_{y, \text { ref }} \frac{\partial w_{\alpha}}{\partial y}+\frac{\partial j_{y, \alpha}}{\partial y}-\sigma_{\alpha} & \text { if } \psi=\text { ref } \\ 0 & \text { if } \psi=\text { fur }\end{array}\right.$

$S_{\psi}^{\mathrm{II}}:=\left\{\begin{array}{cl}-\sum_{\alpha=1}^{N_{c}} h_{\alpha}^{0} \sigma_{\alpha}-\sum_{\alpha=1}^{N_{c}} j_{y, \alpha} \frac{\partial h_{\alpha}^{0}}{\partial y}+\sum_{\alpha=1}^{N_{c}} g j_{y, \alpha} & \text { if } \psi=\text { ref } \\ 0 & \text { if } \psi=\text { fur }\end{array}\right.$

The density is denoted as $\rho$ and $v_{y}, v_{z}$ are velocities in $y$ and $z$ direction. Mass fractions of component $\alpha$ are indicated as $w_{\alpha}$. Diffusion flux $j_{y, \alpha}$, source term $\sigma_{\alpha}$, modified stress tensor $\tau^{*}$ as well as conductive and radiative heat fluxes $q_{y}^{(c)}, q_{y}^{(r)}$ are discussed below. $T$ and $p$ indicate temperature and pressure whereas $c_{p}$ and $g$ symbolize heat capacity and earth acceleration. Pure components enthalpies are represented by $h_{\alpha}^{0} . I$ and $I_{b}$ denote radiative intensity and radiative intensity of a black body whereas $s$ and $\kappa$ represent radiation direction and radiative absorption coefficient.

The energy balance contains advection terms, pressure work, conduction, radiation, the enthalpy change due to chemical reactions, enthalpy diffusion, volume work due to buoyancy for the upright orientation as well as a dissipation term. Pressure, diffusion and dissipation terms are of secondary importance compared to the other contribuents in the energy balance and are introduced for consistency of the boundary layer model formulation. The RTE contains the emission term as a function of the blackbody intensity $I_{b}$ as well as an absorption term of incoming radiation.

The boundary layer formulation implies a constant pressure across the cross sectional area (Eq. (2d)). The ideal gas law and the Shomate equation are used for density and heat capacity calculations [44]. As a consequence of the ideal gas law, specific enthalpies of pure substances (index 0) are used in the energy balance above. Fourier's law, Newton's law and Fick's law are used for heat, momentum and species diffusion. Additional effects such as thermodiffusion (Soret effect) and heat transfer due to concentration gradients (Dufour effect) are negligible compared to the other heat and mass transfer phenomena.

The boundary layer flow (BLF) assumption reduces the complex expressions of generalized Newton's law to a single expression: $\tau^{*}=\eta$ $\partial v_{z} / \partial y$ [45]. The viscosity of the gas mixture is obtained from Wilke's mixing rule which is based on pure component data [46-48]. Fick's diffusion using an effective diffusivity for multicomponent mixtures is preferred over Maxwell-Stefan (MS) diffusion because the increase in accuracy using MS diffusion comes at the expense of disproportionally higher computational cost due to the strong concentration dependencies. The Fuller equation is used for the derivation of the underlying binary diffusion coefficients that are required in the effective diffusivity approach $[49,47]$. The diffusive fluxes are calculated as: $j_{y, \alpha}=-D_{\alpha, \text { eff }} \rho \partial w_{\alpha} / \partial y$. Thermal conductivities that are required for Fourier's law are obtained from kinetic theory of gases: $q_{y}^{(c)}=-\lambda \partial T / \partial y$ [48]. Consequently, two unknowns remain in the conservation laws in Eq. (2): the source term in the species mass balance $\sigma_{\alpha}$ as well as the divergence of the radiative heat flux vector in the energy balance $\partial q_{y}^{(r)} / \partial y$. Both are discussed below in combination with an analysis of the relevance of radiative heat transfer and a model validation of the reaction rate expressions. Prior to that, the solution strategy is outlined.

\subsection{Solution strategy}

Particular emphasis is added on the balance of model details versus simplifying assumptions: fast computation, suitability for process optimization as well as direct accessability and modularity of the modeling equations in the code lead to an implementation in Matlab/CasADi [50]. For this purpose, the equation system (2) with Eq. (3) is discretized in finite volumes (FV) according to Fig. 2: the boundary layer formulation is exploited for the solution of the system of nonlinear partial differential equations as follows. The equations are discretized manually in $y$-direction assuming piecewise constant state functions
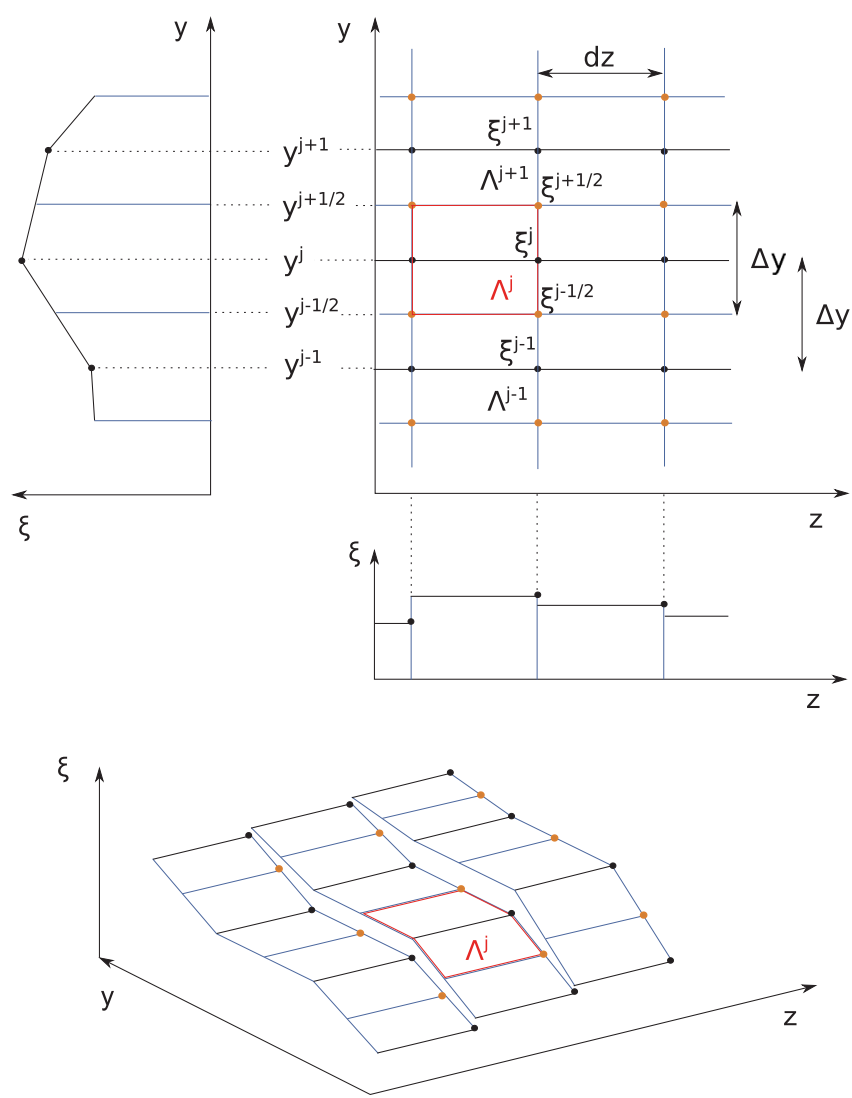

Fig. 2. Discretization scheme in parabolic flow: piece-wise linear functions are assumed in $y$-direction and piece-wise constant states in $z$ for an arbitrary state $\xi$. A finite volume element $\Lambda^{j}$ is highlighted in red. (For interpretation of the references to colour in this figure legend, the reader is referred to the web version of this article.) 
yielding a differential algebraic system. Subsequently, the equations are integrated using state-of-the-art integrators such as IDAS [51]. Inspiration is taken from the SIMPLE(R) algorithms where the pressure drop is obtained as an adjustment parameter to fulfill the continuity equation [52]: the transverse velocity variables are defined at the element boundaries such that one continuity equation remains for the derivation of the pressure drop in the principal flow direction $z$. Consequently, continuity equations are used as algebraic equations for velocity components $v_{y}$ and pressure drop $\partial p / \partial z$. Additional algebraic equations are introduced for the solution of the RTEs that are discussed in more detail below. Large errors due to the discretization scheme are excluded with a grid study: manual discretization into seven crosssectional elements results in a deviation of $2.3 \%$ from the Richardson extrapolate at an infinitely fine mesh size [53].

\subsubsection{Radiative heat transfer}

Radiative heat transfer is often neglected in reactor models or lumped into an effective thermal conductivity e.g. for fixed bed reactors $[35,54]$. A more recent study includes radiation into the model of a channel geometry but applies a truncation of radiative flux in axial direction to reduce the computational cost [55]. In this contribution, however, no additional assumption regarding the evaluation of the radiative heat flux is required due to the BLF assumption - temperature gradients in transverse direction are significantly larger than in axial direction: Eq. (2e) contains a term for the divergence of the radiative heat flux vector, $\nabla \cdot \mathbf{q}^{(r)}$, where the assumption of radiative heat flux only in $y$-direction has already been made due to the BLF. Therefore, the term $\partial q_{y}^{(r)} / \partial y$ remains which, however, does not apply for radiative intensity $I$ which is integrated for the entire solid angle space. The divergence of the radiative heat flux vector $\partial q_{y}^{(r)} / \partial y$ is linked with the radiative intensities - that are obtained as solutions of the RTEs - via directional integration: In principle, the RTE is a five-dimensional equation: three spatial and two directional coordinates describe the change of radiative intensity $\mathrm{d} I / \mathrm{d} s$ along a certain direction $s$ at a local point. Prior to a spatial discretization and solution of the system of partial differential equations (Eq. (2)), the RTE (Eq. (2f)) is discretized and integrated directionally. Complementary to the FV scheme of the spatial discretization, the channel geometry enables the discretization of the RTE into two solid angles $\Omega_{k}, k \in[+,-]$ with the FV assumption of a constant intensity per solid angle [56]. Recalling the directionally integrated RTE in symbolic notation in combination with summation over all solid angles $\Omega_{k}$ (Eq. (4)) leads to an expression for the divergence of the radiative heat flux (Eq. (6)):

$\mathbf{s}_{k} \cdot \nabla I_{k}=\Omega_{k} \kappa\left(I_{b}-I_{k}\right) \quad \mid \sum_{k}$

and with $\sum_{k} \mathbf{s}_{k} \cdot \nabla I_{k} \equiv \nabla \cdot \mathbf{q}^{(r)}$

$\nabla \cdot \mathbf{q}^{(r)}=\sum_{k}\left(\Omega_{k} \kappa\left(I_{b}-I_{k}\right)\right)$.

Using Gauss' integral law and an UPWIND step scheme, this equation is integrated spatially for a volume element $\Lambda$ and a solid angle $\Omega_{k}$

$I_{\Lambda k}=\frac{\Omega_{k} \kappa_{\Lambda} V_{\Lambda} I_{b \Lambda}+\sum_{j, \text { in }} I_{j k}\left|\mathbf{s}_{k} \cdot \hat{\mathbf{n}}_{j}\right| A_{j}}{\Omega_{k} \kappa_{\Lambda} V_{\Lambda}+\sum_{j, \text { out }}\left(\mathbf{s}_{k} \cdot \hat{\mathbf{n}}_{j}\right) A_{j}}$

resulting in $k$ algebraic equations per volume element that are solved simultaneously during the integration of the differential algebraic system. $V_{\Lambda}$ is the volume of finite volume element $\Lambda$. Once all intensities $I_{\Lambda k}$ for an element $\Lambda$ are obtained, they are combined in the integrated energy balance as
$\int_{V_{\Lambda}} \nabla \cdot \mathbf{q}^{(r)} \mathrm{d} V=\sum_{k} \Omega_{k} \kappa_{\Lambda} V_{\Lambda}\left(I_{b \Lambda}-I_{\Lambda k}\right)$.

In order to be able to use this relationship, however, the grey gas assumption is applied in Eq. (2f) meaning that the absorption of the gas is a constant fraction of the blackbody spectrum for all wavelengths. In its general form, the RTE is wavelength dependent which is particularly relevant for accurate absorption description of gases that absorb and emit in discrete wavelength bands due to their quantized energy levels. In order to calculate the heat transfer inside the reforming-furnace reactor, the overall heat that is transferred is of interest in contrast to specific energy bands. Commonly investigated substances are $\mathrm{CO}_{2}$ and $\mathrm{H}_{2} \mathrm{O}$ due to their wide application range in combustion and strong absorption. In order to include also $\mathrm{CO}$ and $\mathrm{CH}_{4}$ as well as the temperature dependence of the absorption properties of the substances, a Planck mean absorption coefficient is used. It is derived from high resolution spectroscopic data that is contained in databases such as HITRAN or HITEMP [57-60]. Data in the high temperature database HITEMP does not contain all species of interest and data in HITRAN is available at standard conditions of $T^{\ominus}=298 \mathrm{~K}$ and $p^{\ominus}=1013 \mathrm{hPa}$. However, the line spectra are transformed with good accuracy for this engineering application to higher temperatures and pressures through the calculation of partition sums at different temperature levels based on Eq. (9) [61].

$S_{i j}(T)=S_{i j}\left(T^{\ominus}\right) \frac{Q\left(T^{\ominus}\right)}{Q(T)} \frac{\mathrm{e}^{\frac{-h c E^{\prime \prime}}{k T}}}{\mathrm{e}^{\frac{-h c E^{\prime \prime}}{k T^{\ominus}}}} \frac{1-\mathrm{e}^{\frac{-h c \eta}{k T}}}{1-\mathrm{e}_{k T^{\ominus}}}$

Scattering is of secondary importance compared to absorption and emission [62]. The wall boundary condition of the RTE requires emissivities of the surface: The catalyst $\mathrm{Ni}$ in combination with the support material of $\mathrm{Al}_{2} \mathrm{O}_{3}$ has an estimated emissivity between 0.3 and 0.5 but carbon deposits on the catalyst surface from side reactions as well as radiative absorption of adsorbed reaction intermediates cannot be excluded under operating conditions. Therefore an estimated surface emissivity of 0.5 is justified [63].

Dimensionless numbers are useful for the identification of flow and transport regimes. For radiative heat flux there exists the dimensionless Planck number ( $\mathrm{Pl})$ which represents a conduction-to-radiation ratio and which is obtained anologously to the Reynolds number during the transformation of the energy balance in BLF to its dimensionless form. An analog dimensionless ratio of overall heat fluxes $\mathrm{Pl}_{\text {sim }}$ is defined in order to apply this idea to simulation experiments directly:

$\mathrm{Pl}_{\text {sim }}:=\frac{\int_{V_{\text {reac }}} \nabla \cdot \mathbf{q}^{(c)} \mathrm{d} V}{\int_{V_{\text {reac }}}\left(\nabla \cdot \mathbf{q}^{(c)}+\nabla \cdot \mathbf{q}^{(r)}\right) \mathrm{d} V} \cdot 100 \%$.

Fig. 3 proves the significance of the radiation model: $\mathrm{Pl}_{\text {sim }}$ values versus reactor width for are shown for the furnace side of the reactor. Provided that a complete combustion of methane with air has occurred which corresponds to the maximum radiative heat transfer potential

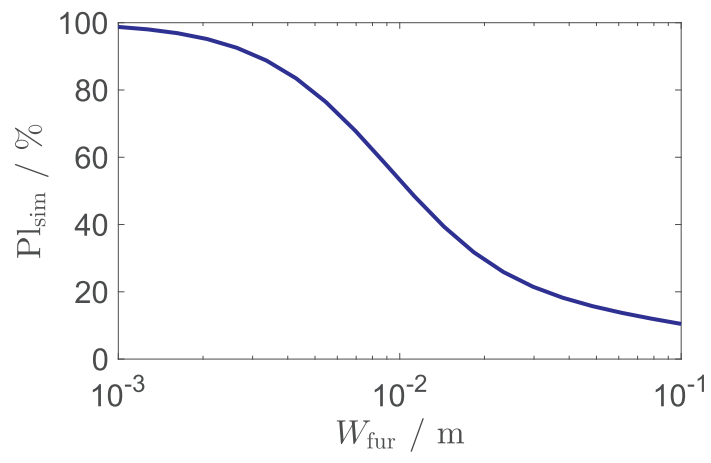

Fig. 3. $\mathrm{Pl}_{\text {sim }}$ versus width $W_{\text {fur }}$ for the furnace side. 
due to maximum partial pressures of absorbing-emitting $\mathrm{CO}_{2}$ and $\mathrm{H}_{2} \mathrm{O}$, the furnace gas has the following molar composition: $x_{\mathrm{N}_{2}}$ $=0.73, x_{\mathrm{H}_{2} \mathrm{O}}=0.18$ and $x_{\mathrm{CO}_{2}}=0.09$. The gas enters at a combustion temperature of $1800 \mathrm{~K}$ and is cooled down due to the reforming reaction in the adjacent compartment. As shown in Fig. 3, conduction dominates heat transfer in the flue gas in the mm-region. At $4 \mathrm{~mm}$, conduction accounts for $80 \%$ and beyond $1 \mathrm{~cm}$, radiative heat transfer accounts for more than $50 \%$ of the total heat transferred. Beyond $3 \mathrm{~cm}$, radiative heat transfer accounts for more than $80 \%$ of heat transfer from the flue gas to the wall and the reforming side. The radiative heat transfer model is therefore essential for endothermic reactor design studies that are not limited to microchannel dimensions where radiative heat transfer may be negligible.

\subsection{Reaction kinetics and model validation}

The three most relevant chemical reactions - reforming, total reforming and water gas shift reaction - were introduced in Eq. (1). Several reaction kinetics are proposed in literature with the most commonly used being the one by Xu and Froment which was developed in the 1980's where they also discussed diffusion limitations in reactor modelling [64,33]. More recent studies propose either microkinetic reaction mechanisms with elementary step kinetics - that have also been applied to MSR with a BLF model on a Rh catalyst - or more simplified kinetics based on a single rate determining step which is the activation of $\mathrm{CH}_{4}$ [65-68]. Because of its wide acceptance and its application for both packed bed and wall reactor models, the kinetics of $\mathrm{Xu}$ and Froment are used throughout this contribution [34].

The source term $\sigma_{\alpha}$ is zero except at the wall element(s) depending on the number of discretization elements and catalyst thickness. Xu's Langmuir-Hinshelwood type rate expressions in $\mathrm{kmolkg}_{\text {cat }}^{-1} \mathrm{~h}^{-1}$ are given as
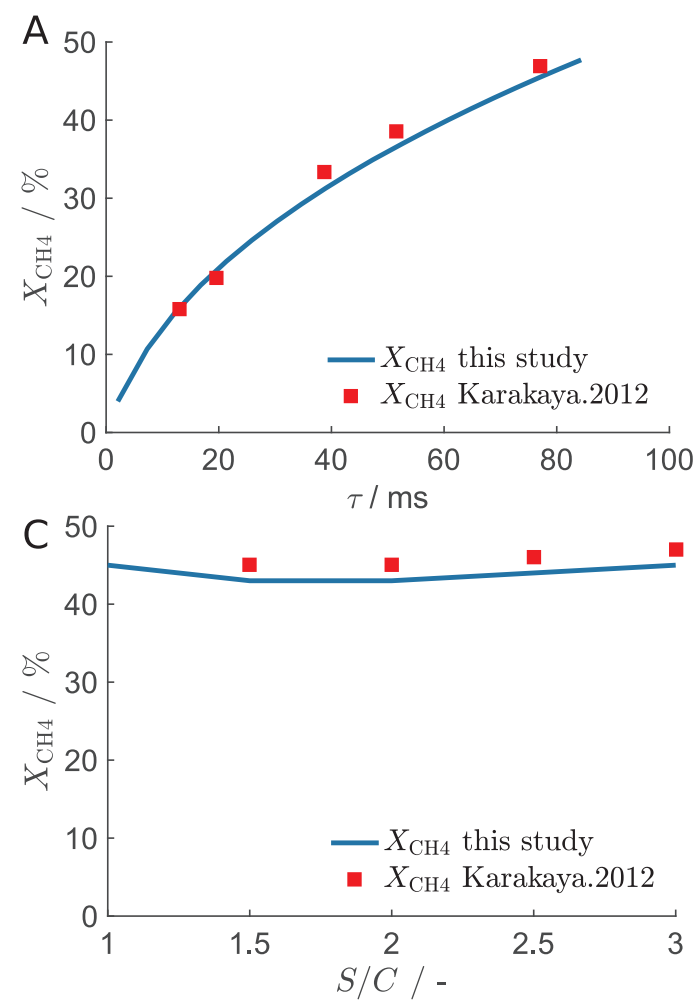

$r_{(\mathrm{a})}=\frac{k_{1}}{p_{\mathrm{H}_{2}}^{2.5}}\left(p_{\mathrm{CH}_{4}} p_{\mathrm{H}_{2} \mathrm{O}}-\frac{p_{\mathrm{H}_{2}}^{3} p_{\mathrm{CO}}}{K_{1}}\right) \frac{1}{(D E N)^{2}}$

$r_{(\mathrm{b})}=\frac{k_{2}}{p_{\mathrm{H}_{2}}}\left(p_{\mathrm{CO}} p_{\mathrm{H}_{2} \mathrm{O}}-\frac{p_{\mathrm{H}_{2}} p_{\mathrm{CO}_{2}}}{K_{2}}\right) \frac{1}{(D E N)^{2}}$

$r_{(\mathrm{c})}=\frac{k_{3}}{p_{\mathrm{H}_{2}}^{3.5}}\left(p_{\mathrm{CH}_{4}} p_{\mathrm{H}_{2} \mathrm{O}}^{2}-\frac{p_{\mathrm{H}_{2}}^{4} p_{\mathrm{CO}_{2}}}{K_{3}}\right) \frac{1}{(D E N)^{2}}$

with $\quad D E N:=1+K_{\mathrm{CO}} p_{\mathrm{CO}}+K_{\mathrm{H}_{2}} p_{\mathrm{H}_{2}}+K_{\mathrm{CH}_{4}} p_{\mathrm{CH} 4}+K_{\mathrm{H}_{2} \mathrm{O}} p_{\mathrm{H}_{2} \mathrm{O}} / p_{\mathrm{H}_{2}}$.

Details on the parameters as well as effectiveness factors of the kinetic model are taken directly from $\mathrm{Xu}[64,33]$. In order to use them in the source term $\sigma_{\alpha}$ in the species mass balance (Eq. (2b)), a unit conversion is necessary to obtain a volumetric mass-based expression in $\mathrm{kg} \mathrm{m}^{-3} \mathrm{~s}^{-1}$.

A comparison of modelling results with experimental data in literature for $S / C=3 / 1$, isothermal reaction conditions at $T_{\text {ref }}=1023 \mathrm{~K}$ and a catalyst amount of $m_{\mathrm{Ni}}=14.2 \mathrm{mg}$ is presented in Fig. 4 [69]. The agreement of simulation and experimental data is excellent with regards to conversion of the limiting reactant $\mathrm{CH}_{4}$ (Fig. 4A) and acceptable for the selectivity towards CO (Fig. 4B). Similar results are obtained from comparison at other $S / C$ ratios and residence times. In contrast to experimental data, simulation selectivities and conversions approach thermodynamic equilibrium as shown in Fig. 7 indicating thermodynamically consistent reaction kinetics. The literature experimental data in Fig. 4B rises marginally and levels off at $S_{\mathrm{CO}}=38 \%$ which Karakaya et al. justify with kinetic effects of the water-gas-shift reaction that cannot, however, not be further validated with other sources. Comparing simulation with literature conversions and selectivities for different steam-to-carbon ratios (Fig. 4C and D) reveals good agreement between simulation and literature with a minimal underestimation of conversion by $2-4 \%$ and a slight overestimation of selectivities by $3-6 \%$. Keeping in mind the contrasting opinions on the
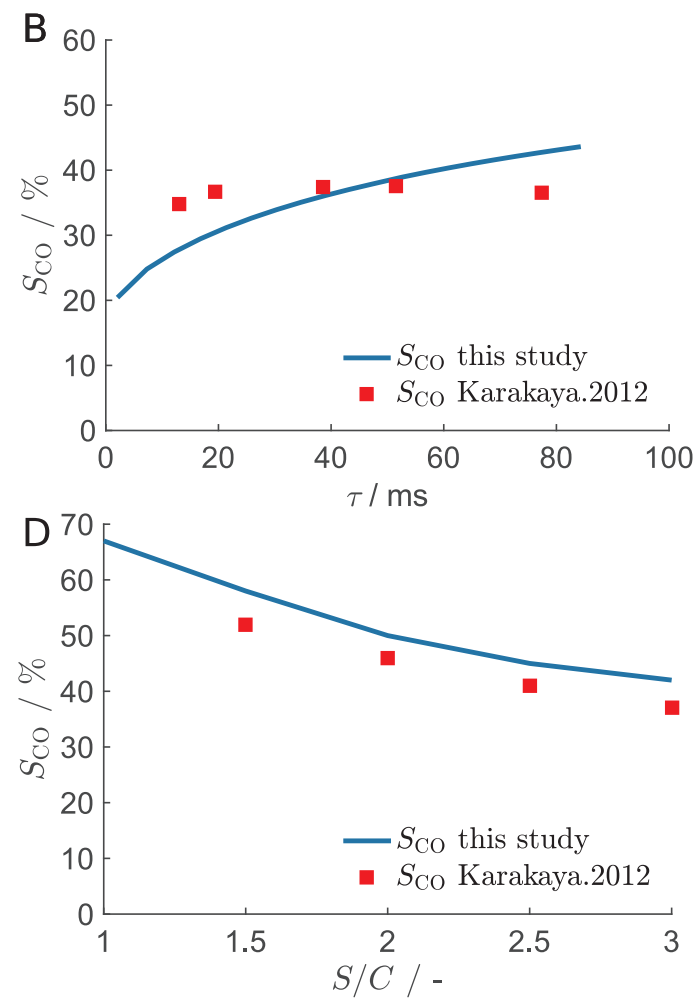

Fig. 4. Validation of reactor model with experimental data from literature: conversion of limiting reactant $\mathrm{CH}_{4}(\mathrm{~A}, \mathrm{C}$ ) and selectivity towards target product $\mathrm{CO}$ (B, D) for varying space times and steam-to-carbon $(S / C)$ ratios at isothermal $\left(T_{\text {ref }}=1023 \mathrm{~K}\right)$ and ambient pressure reaction conditions [69]. Space times $(\mathrm{A}$, B) are compared at $S / C=3$ and steam-to-carbon ratios (C, D) at $\tau=77 \mathrm{~ms}$. 
reaction kinetics that were outlined above and the focus of this work on reactor design, the agreement between literature and simulation data upon usage of kinetics by $\mathrm{Xu}$ and Froment is considered adequate. Further mechanistic analysis and validation with experimental data are beyond the scope of this work and may be addressed in the future.

\section{Results \& discussion}

In line with the proposed approach, the results are structured into two parts: the first section serves as an identification of the optimal design parameters of the reforming compartment assuming a constant wall boundary temperature. Subsequently, the feasibility of the identified designs is analyzed in a second part using a coupled model of reforming and furnace side.

\subsection{Reforming compartment design}

As introduced in the section above, two design and two operating parameters are decisive for the reforming compartment design: $L$, $W_{\text {ref }}, F_{\text {ref }}$ and $S / C$. Additionally, the operating temperature is controlled via the wall boundary temperature $T_{w}$. A preheated feed at $900 \mathrm{~K}$ is assumed and the length is set to $0.5 \mathrm{~m}$. Space time is thus varied by variation of the feed volume flow $F_{\text {ref }}$. Consequently, the catalyst volume is constant throughout the entire design study because a change in width of the reactor does not affect the catalyst volume. Thereby the analysis and design optimization focus on transport limitations. Generally, low operating temperatures reduce formation of coke and energy costs of the process but limit the yield of the endothermic reforming reaction. Furthermore, high $S / C$ ratios prevent coking but limit the yield and require higher temperatures for similar selectivities compared to low $S / C$ ratios as shown in the thermodynamic equilibrium selectivities in Fig. 5. Therefore, two values of $S / C-$ at $3 / 1$ and $1 / 1$ - are investigated first to identify their respective optimal designs which are then compared for varying $S / C$ ratios. Prior to that, the key performance indicators of the channel reactor are defined.

\subsubsection{Performance indicators for the autothermal channel reactor}

In general, flow reactors are characterized by the space time $\tau$ that was introduced above and space time yield of product $i-S T Y_{i}-$ defined as

$S T Y_{\mathrm{i}}:=\frac{n_{\mathrm{i}}(z=L)-n_{\mathrm{i}}(z=0)}{V_{\text {cat }}}$

$[70,71]$. Varying the width of the reforming channel, the space time remains constant because reactor volume and volume flow increase by the same factor for every inlet velocity. Space time $\tau$ is therefore used as a design coordinate. MSR is commonly used for synthesis gas production and is described with an additional performance indicator [72]: the stoichiometric number $S N$ that is defined for the product stream $\left(n_{i}=n_{i}(z=L)\right)$ as

$S N:=\frac{n_{\mathrm{H}_{2}}-n_{\mathrm{CO}_{2}}}{n_{\mathrm{CO}}+n_{\mathrm{CO}_{2}}}$.

Fig. 6A illustrates $S N$ for a range of space times from 20 to $1000 \mathrm{~ms}$ and reforming channel half-widths from $10^{-3}-10^{-1} \mathrm{~m}$ in a semilogarithmic graph. It is evident that $S N$ does not describe the selectivity of the reaction based on the graphs of the corresponding molar fractions at the reactor outlet of $\mathrm{H}_{2}$ (Fig. 6B), $\mathrm{CO}$ (Fig. 6C) and $\mathrm{CO}_{2}$ (Fig. 6D). Region I in each plot highlights the drawback of using $S N$ as a performance measure: as one proceeds in the direction indicated by the arrows, the desired product molar fraction $\mathrm{CO}$ decreases but the byproduct of $\mathrm{CO}_{2}$ increases resulting in a nearly constant $S N$ value. Removal of $\mathrm{CO}_{2}$, however, requires a shift reactor or a Rectisol process in industrial plants leading to disadvantages in the overall process context [5]. Since it does not describe product quality appropriately, the $S N$ is not a suitable indicator to address MSR for synthesis gas production.

In order to include the selectivity and normalize the reactor outlet with the reactant amount in the performance indicator, the yield of $\mathrm{CO}$ $-Y_{\mathrm{CO}}-$ is analyzed along with the space time yield. It is defined as the product of selectivity of $\mathrm{CO}$ and conversion of $\mathrm{CH}_{4}: Y_{\mathrm{CO}}:=X_{\mathrm{CH}_{4}} S_{\mathrm{CO}}$. Selectivity and conversion are defined as

$$
\begin{aligned}
& X_{\mathrm{CH}_{4}}:= \frac{n_{\mathrm{CH}_{4}}(z=0)-n_{\mathrm{CH}_{4}}(z=L)}{n_{\mathrm{CH}_{4}}(z=0)} \\
& S_{\mathrm{CO}}:=\frac{n_{\mathrm{CO}}(z=L)-n_{\mathrm{CO}}(z=0)}{\sum_{\text {prod.i }} n_{\mathrm{i}}(z=L)-n_{\mathrm{i}}(z=0)} .
\end{aligned}
$$

An additional performance number is introduced for the furnace side in order to identify the best furnace configuration: yield and space time yield are normalized with the furnace side volume flow $F_{\text {fur }}$ representing the fuel efficiency of the furnace design $\widehat{Y}_{\mathrm{CO}}$ and $S \widehat{T} Y_{\mathrm{CO}}$ :

$\widehat{Y}_{\mathrm{CO}}:=\frac{Y_{\mathrm{CO}}}{F_{\text {fur }}} \quad$ and $\quad S \widehat{T} Y_{\mathrm{CO}}:=\frac{S T Y_{\mathrm{CO}}}{F_{\text {fur }}}$.

\subsubsection{Steam-to-carbon ratio of $3 / 1$}

Blue symbols in Fig. 7 illustrate the thermodynamic equilibrium values for $S_{\mathrm{CO}}$ as well as the maximum selectivity and yield values from simulation out of all designs for $S / C$ ratios of $3 / 1$ and $1 / 1$. With respect to the low $S / C$ ratio, simulation results are within a $2-13 \%$ range of the thermodynamic equilibrium indicating that maximum values of $S_{\mathrm{CO}}$ are attainable for the investigated space times and that the kinetics are thermodynamically consistent. An exception is the selectivity at $S / C=1 / 1$ at $T_{\mathrm{w}}=900 \mathrm{~K}$ where maximum space time and minimum channel width do not suffice to attain the equilibrium value. At a $S / C$ ratio of $3 / 1$, however, the deviation from the thermodynamic equilibrium value increases with temperature. The corresponding yields at high temperatures are close to the $S_{\mathrm{CO}}$ values since maximum conversion of $\mathrm{CH}_{4}$ is attained.

The design space of $W_{\text {ref }}$ and space time $\left(F_{\text {ref }}\right)$ for a wall boundary temperature of $1000 \mathrm{~K}$ and a $S / C$ ratio of $3 / 1$ is shown in more detail in Fig. 8. As shown in Fig. 7, the effect of increasing wall temperature on the yield is small at high $S / C$ ratios. Therefore the design analysis is carried out for $T_{w}=1000 \mathrm{~K}$. The two graphs Fig. 8A and B illustrate $Y_{\mathrm{CO}}$ and $S T Y_{\mathrm{CO}}$. A region with maximum (I), intermediate (II) and with lowest values (III) are indicated with dotted lines. The maximum yield in Fig. $8 \mathrm{~A}$ is not at maximum $\tau$ and minimum $W_{\text {ref }}$ contradicting the asnarrow-as-possible assumption of microchannel reactor design of excluding cross-sectional transport limitations and increasing space time to achieve an optimal yield. To understand this behavior, conversion and selectivity are illustrated in Fig. $8 \mathrm{C}$ and D: the conversion $X_{\mathrm{CH}_{4}}$ in Fig. 8C reaches its maximum at small half-widths below $1 \times 10^{-2} \mathrm{~m}$ again indicated with (I). The selectivity $S_{\mathrm{CO}}$ in Fig. 8D shows a similar behavior but it exhibits a plateau that is $1.5 \%$ above the other selectivities at half-widths between $2 \times 10^{-3} \mathrm{~m}$ and $1 \times 10^{-2} \mathrm{~m}$ indicating a transport limitation for $\mathrm{H}_{2} \mathrm{O}$ in this design space (I): $\mathrm{H}_{2} \mathrm{O}$ may

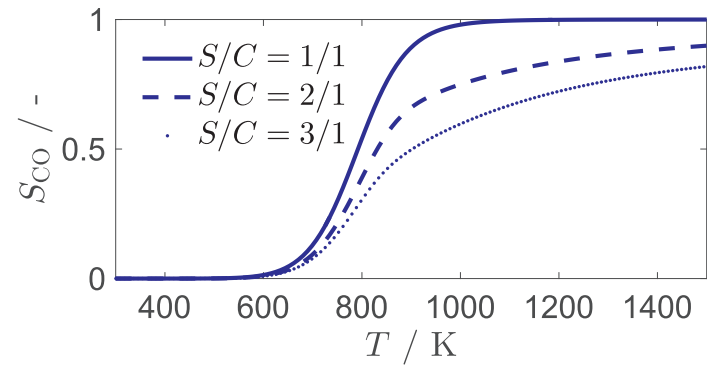

Fig. 5. Thermodynamic equilibrium selectivities $S_{\mathrm{CO}}$ for three different $S / C$ ratios: $1 / 1,2 / 1$ and $3 / 1$. 

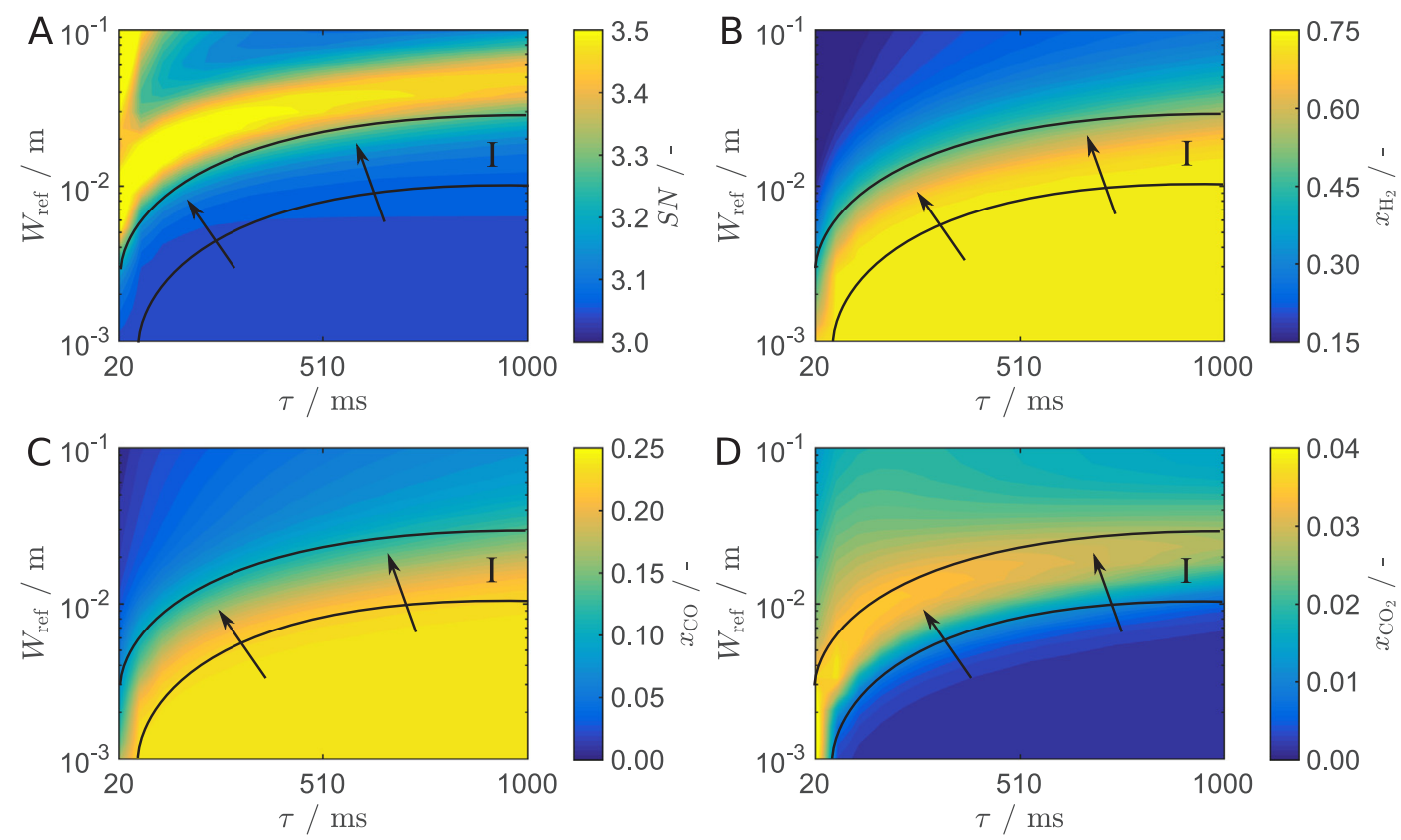

Fig. 6. Stoichiometric number $S N$ (A) and molar fractions of $\mathrm{H}_{2}$ (B), $\mathrm{CO}$ (C) and $\mathrm{CO}_{2}$ (D) for $S / C=1 / 1$ and $T_{w}=1200 \mathrm{~K}$.

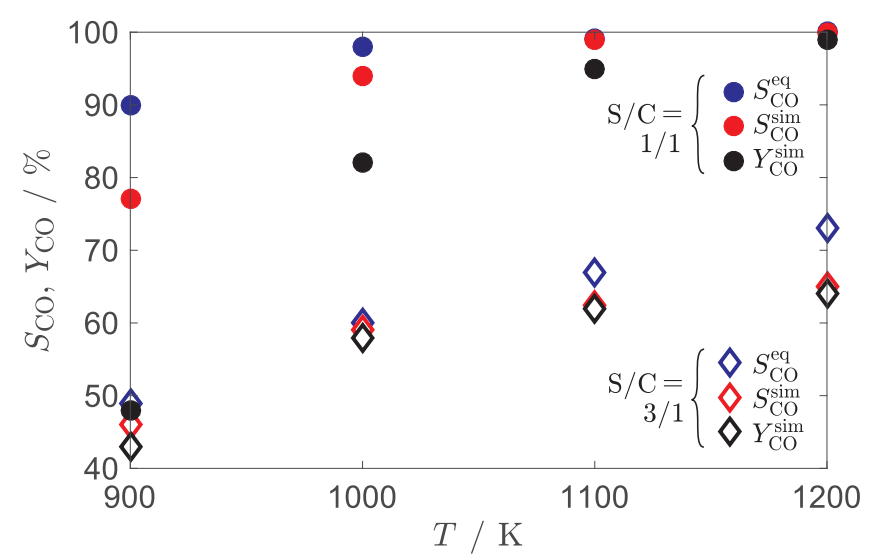

Fig. 7. Selectivities $S_{\mathrm{CO}}$ from simulations (sim) and thermodynamic equilibrium (eq) values as well as yields $Y_{\mathrm{CO}}$ for two different $S / C$ ratios versus temperature.

be depleted locally shifting the equilibrium towards $\mathrm{CO}$ instead of $\mathrm{CO}_{2}$ due to its lower demand in $\mathrm{H}_{2} \mathrm{O}$. The reaction is not limited by heat transfer in this region as justified by the average outlet temperature plot Fig. 8E: the maximum region is once again in the lower right corner (I). A comparison of the reaction kinetics described above and an analysis of the Thiele modulus may lead to further insights but lie beyond the scope of this contribution. Within a second region in Fig. 8E (*), conversion is decreasing sharply but still consuming part of the available thermal energy. In the adjacent region (**), the temperature is increasing because conversion is almost zero due to large diffusion lengths and thus no heat of conversion is consumed.

$S T Y_{\text {CO }}$ attains its maximum value at low space times and high halfwidths corresponding to large reactant volume flows. The region of optimal values is split into two: one below half-widths of $1 \times 10^{-2} \mathrm{~m}$ where heat transfer is high and large conversions are attained and one above $2 \times 10^{-2} \mathrm{~m}$ where conversion is low but volume flows are high resulting in a high $S T Y_{\mathrm{CO}}$. The advantage of an increase in yield from the lower maximum region (I) of $S T Y_{\mathrm{CO}}$ towards higher space times is dominated by lower flow rates and thus $S T Y_{\mathrm{CO}}$ decreases with space time. A comparison with the experimental data that was used for model validation shows that conversions and selectivities in the simulation attain values that are closer to thermodynamic equilibrium than the experimental results due to a larger range of space times [69]. Experimental data for a microchannel reactor system of Velocys, equally seem to attain values close to thermodynamic equilibrium but the authors do not provide sufficient data for a thorough comparison [22].

\subsubsection{Steam-to-carbon ratio of $1 / 1$}

At $S / C$ ratios of $1 / 1$, the attainable yields are significantly above the ones of $S / C=3 / 1$ in the considered temperature spectrum as demonstrated in Fig. 7. With the exception of $900 \mathrm{~K}$ where longer space times would increase yields, $Y_{\mathrm{CO}}$ values are close to thermodynamic equilibrium and high conversions of $\mathrm{CH}_{4}$ close to unity are attained. The analysis of the design space is repeated for the maximum wall temperature of $1200 \mathrm{~K}$ and the lower limit of the $S / C$ ratio of $1 / 1$ in Fig. 9: regions of maximum yield (I) are identical among conversion (Fig. 9C), selectivity (Fig. 9D) as well as the average outlet temperature (Fig. 9E) which is in agreement with literature [22]. Based on the sharp decrease in the reactor outlet temperature in Fig. $9 \mathrm{E}$ that is indicated with the dotted line, the conversion is limited by heat transfer for shorter space times and larger widths beyond region (I). STY $Y_{\mathrm{CO}}$ exhibits similar to high $S / C$ ratios two regions of maximum values (I): one at half-widths below $1 \times 10^{-2} \mathrm{~m}$ and thus small volume flows and one beyond $2 \times 10^{-2} \mathrm{~m}$ where conversions are low due to heat transfer limitations but volume flows are high and the reaction consumes the heat provided in the preheating step. As shown for high $S / C$ ratios, both optimal regions do not overlap and a compromise between $Y_{\mathrm{CO}}$ and $S T Y_{\mathrm{CO}}$ has to be identified.

\subsubsection{Identification of optimal design}

In order to identify the best design independent of a preset $S / C$ ratio, results of $S / C=1 / 1$ are visualized as $S T Y_{\mathrm{CO}}$ versus $Y_{\mathrm{CO}}$ in Fig. 10 (A). $S / C=1 / 1$ is selected because it represents the maximum attainable region - higher $S / C$ result in lower space time yields or lower product yields and are thus located in the bottom left corner of Fig. 10A. Three designs as indicated on the right hand side are selected with maximum $S T Y_{\mathrm{CO}}$ for three different $Y_{\mathrm{CO}}$ at $95 \%, 55 \%$ and $0.5 \%$. Their corresponding half-width and volume flows are summarized in Table 1. The three designs are then compared in terms of $Y_{\mathrm{CO}}$ (Fig. 10B) and $S T Y_{\mathrm{CO}}$ (Fig. 10C) for two temperatures and varying $S / C$ ratios: $\mathrm{D}_{3}$ has the maximum flow rate and width out of the parameter space that was analyzed. Due to its high flow rate, the fluid consumes mostly the 

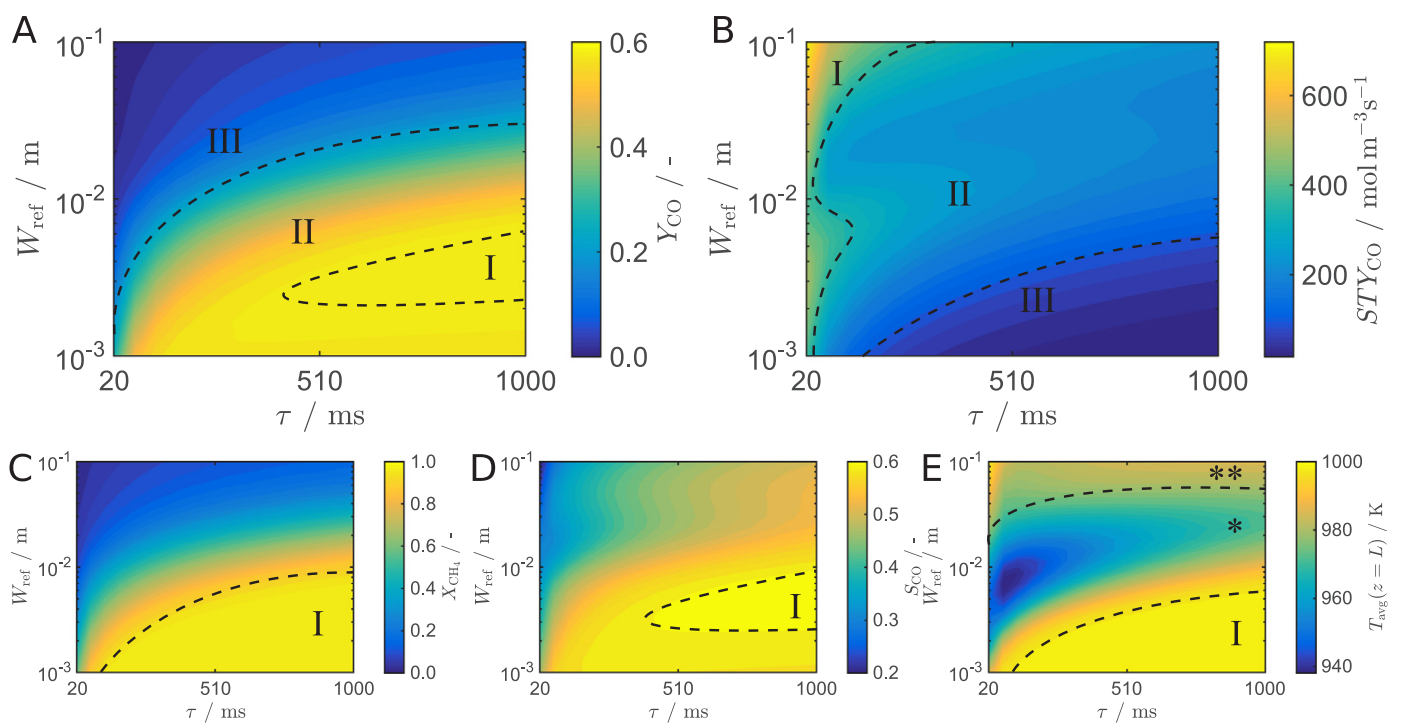

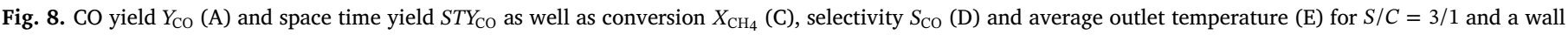
boundary temperature of $1000 \mathrm{~K}$.

energy of the preheating upon entering the reactor. Its heat uptake is very limited and it displays therefore almost no temperature dependence in Fig. 10B and C. Due to its low yield of CO of 0.5\%, it is not considered further for the furnace design. Design $\mathrm{D}_{2}$ is a promising candidate among the three designs for industrial applications as it balances good yield with high space time yield: synthesis gas is a commodity emphasizing product quantity. Design $\mathrm{D}_{3}$ is relevant as soon as high product purities at the expense of a lower $S T Y_{\mathrm{CO}}$ are required.

\subsection{Reactor design: furnace compartment}

Two design parameters - length $L$ and width $W_{\text {ref }}-$ as well as the flow rate $F_{\text {ref }}$ and reforming side feed composition $S / C$ have been identified in the previous section resulting in two optimal designs $\mathrm{D}_{1}$ and $\mathrm{D}_{2}$. Furnace width $W_{\text {fur }}$, flowrate $F_{\text {fur }}$ as well as inlet temperature $T_{\text {fur }}^{\text {(in) }}$ are identified with the coupled reforming-furnace model.

\subsubsection{Width and flue gas volume flow}

The two reforming side configurations $\mathrm{D}_{1}$ and $\mathrm{D}_{2}$ are simulated in combination with the furnace side to analyze if the performance for constant wall temperatures is attainable with a laminar flue gas flow in the furnace compartment. Yields and normalized yields for $S / C=1 / 1$ are shown in Fig. 11 with $\mathrm{D}_{1}$ at the top (Fig. $11 \mathrm{~A}$ and B) and $\mathrm{D}_{2}$ at the bottom (Fig. 11C and D) but the results are equivalent for other $S / C$ ratios and also $S T Y_{\mathrm{CO}}$. $\mathrm{D}_{1}$ which showed high yield and low space time yields attains its maximum $Y_{\mathrm{CO}}$ for any width $W_{\text {fur }}$ ranging from $10^{-3}$ to $10^{-1} \mathrm{~m}$ above a furnace side volume flow of $2 \times 10^{-2} \mathrm{~m}^{3} \mathrm{~s}^{-1}$ (I). The highest yield per fuel input is attained at slightly smaller $F_{\text {fur }}$ and right at the border where the yield reaches its maximum (I): $9 \times 10^{-3}-2 \times 10^{-2} \mathrm{~m}^{3} \mathrm{~s}^{-1}$. $\mathrm{D}_{2}$ does not attain the maximum yield and reaches only $60 \%$ of the maximum yield of $98 \%$. Consequently, the fuel efficiency is decreasing monotonously with increasing $F_{\text {fur }}$. Turbulence, catalytic combustion or higher gas pressures may result in the desired product yields for this design. It is remarkable, however, that there is a slight impact of width highlighted with regions (II) and (III) in Fig. 11B-D. In the lower half of the plots (II), the width of the furnace is small resulting in a narrow channel where conduction dominates heat transfer as confirmed by the simulated Planck number $\mathrm{Pl}_{\text {sim }}$ shown in Fig. 12. Irrespective of the volume flow rate $F_{\text {fur }}$, the Planck number $\mathrm{Pl}_{\text {sim }}$ is unity for widths $W_{\text {fur }}$ in proximity to $10^{-3} \mathrm{~m}-$ conduction
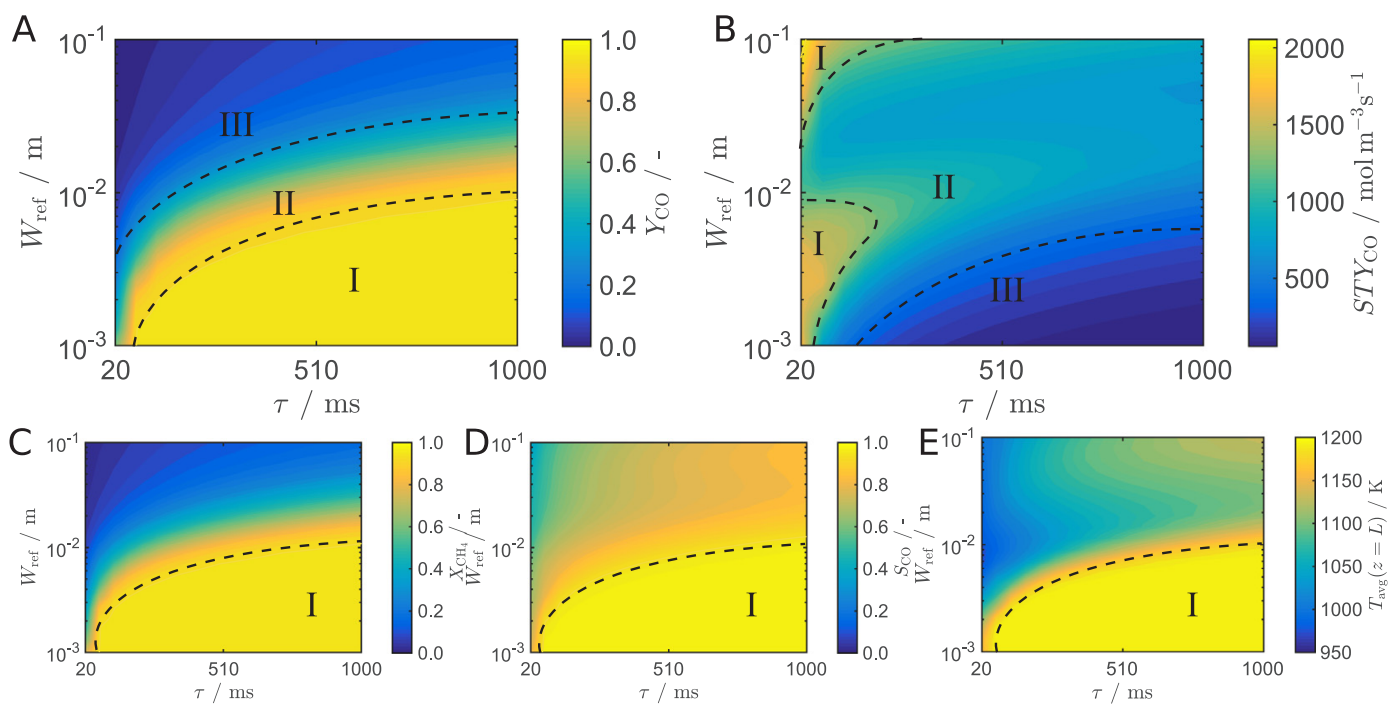

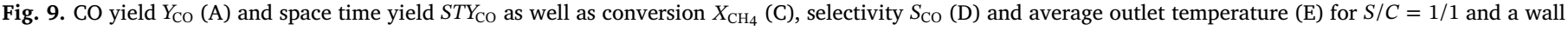
boundary temperature of $1200 \mathrm{~K}$. 

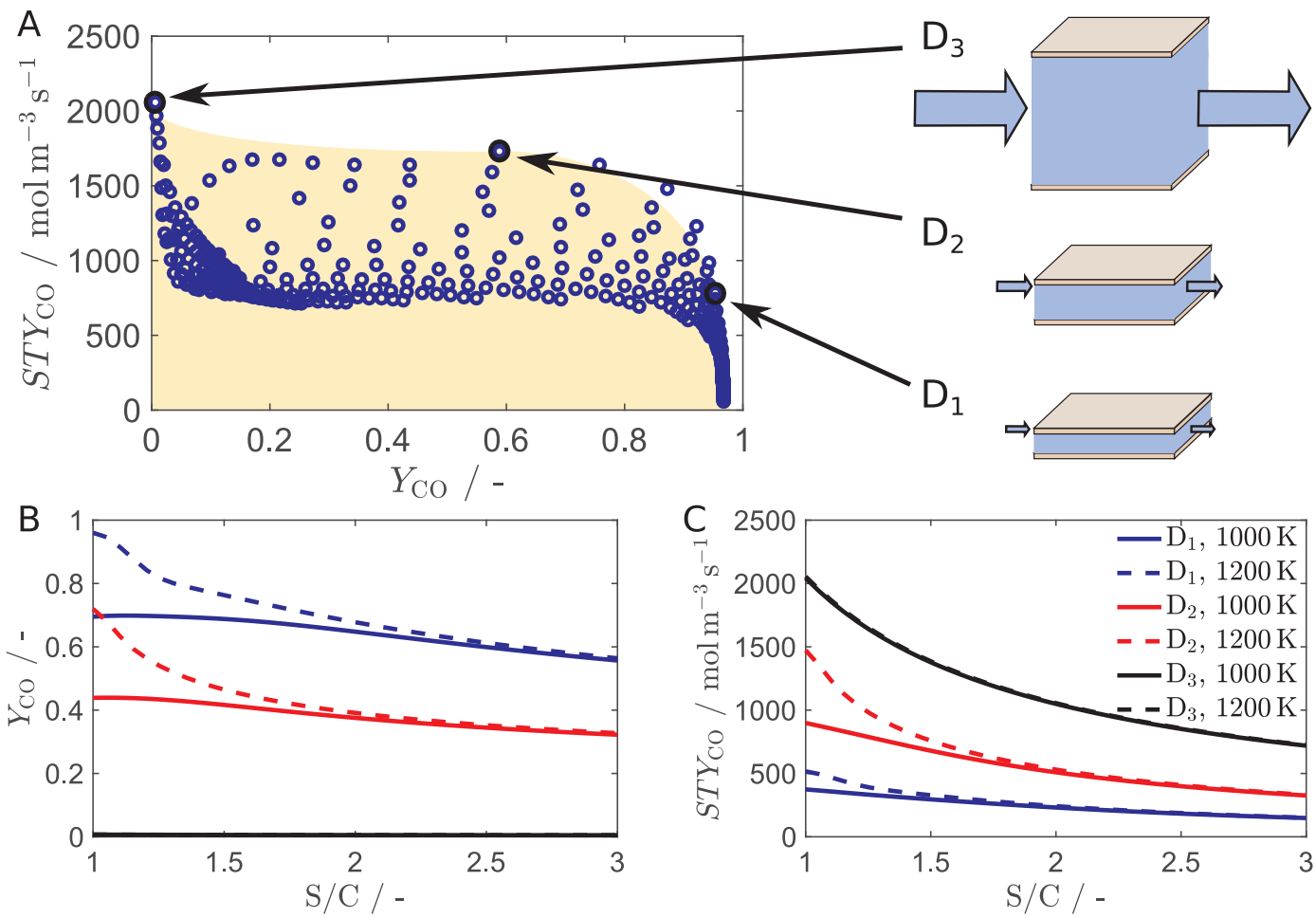

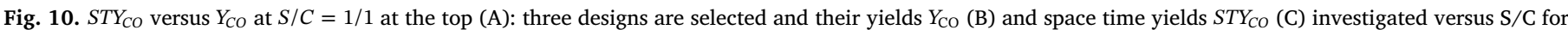
two different wall temperatures $T_{w}$ of 1000 and $1200 \mathrm{~K}$. The yellow shaded region illustrates the feasible region in which all designs are located.

Table 1

Design and operating parameters of reformer designs 1,2 and 3.

\begin{tabular}{llll}
\hline Design & $\begin{array}{l}\tau \\
\mathrm{ms}\end{array}$ & $\begin{array}{l}F_{\text {ref }} \\
\mathrm{m}^{3} \mathrm{~s}^{-1}\end{array}$ & $\begin{array}{l}W_{\text {ref }} \\
\mathrm{m}\end{array}$ \\
\hline 1 & 226 & $9.14 \times 10^{-4}$ & $2.07 \times 10^{-3}$ \\
2 & 123 & $3.51 \times 10^{-3}$ & $4.28 \times 10^{-3}$ \\
3 & 20 & $5.00 \times 10^{-1}$ & $1.00 \times 10^{-1}$ \\
\hline
\end{tabular}
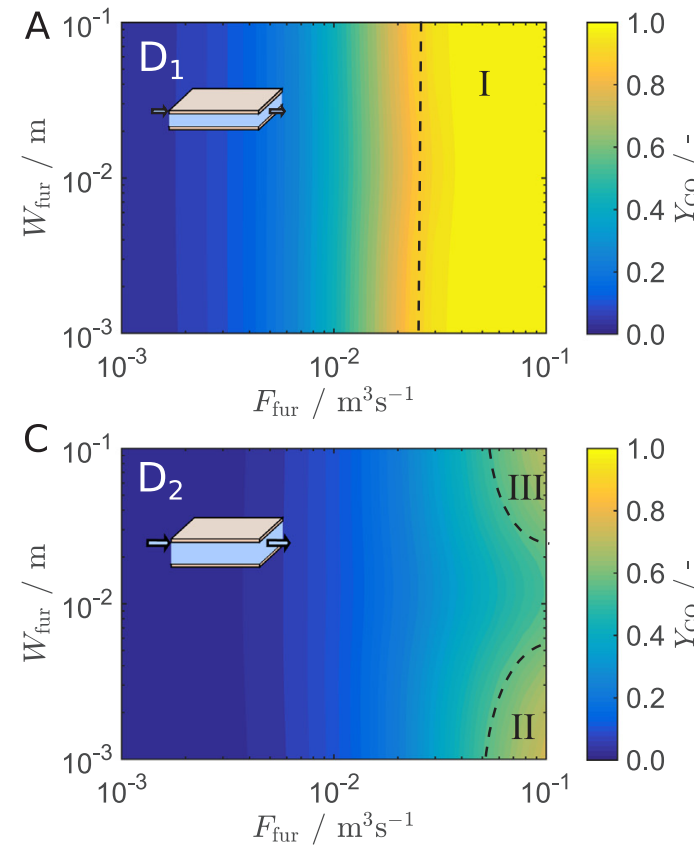

dominates to $100 \%$ - and decreases to $60 \%$ at $10^{-2} \mathrm{~m}$. At $10^{-1} \mathrm{~m}$ it varies between 5 and $20 \%$ meaning that radiative heat transport into the reacting gas is the main mode of heat transfer. As the width of the furnace side increases, the flow velocity decreases for a constant volume flow. Consequently, the upper part of the graphs exhibit large residence times and radiative heat transfer transports the energy to the reforming side wall leading to a second maximum yield in Fig. 11B-D in region III. In summary, the effects of the furnace width for $Y_{\mathrm{CO}}$ is of secondary importance but both low $-W_{\text {fur }} \leqslant 4 \mathrm{~mm}-$ and high widths $-20 \mathrm{~mm} \leqslant W_{\text {fur }}$
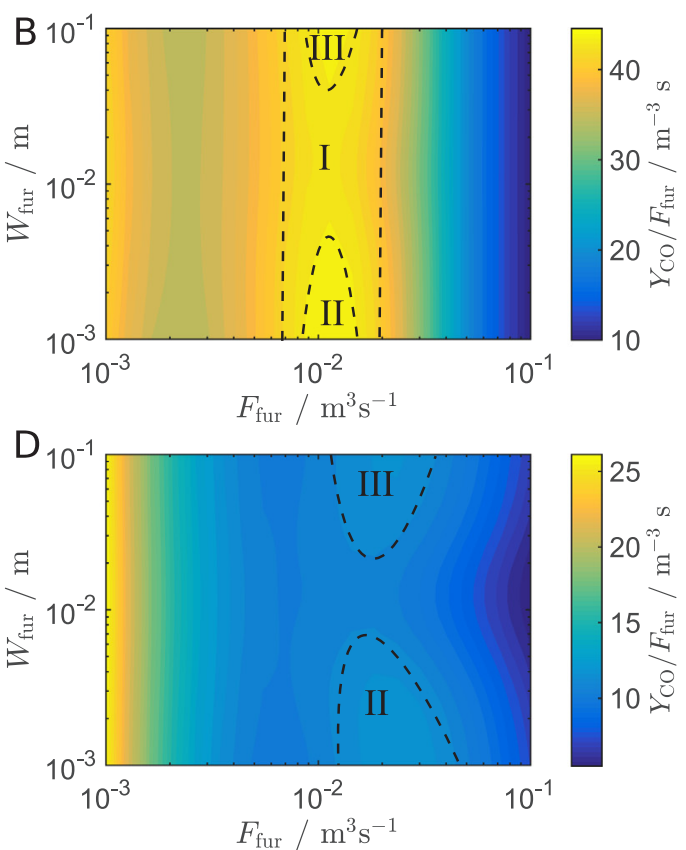

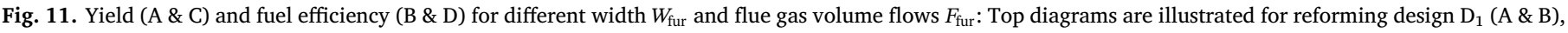
bottom results for design $\mathrm{D}_{2}$ (C \& D). In both cases feed compositions are set to $S / C=1 / 1$. 


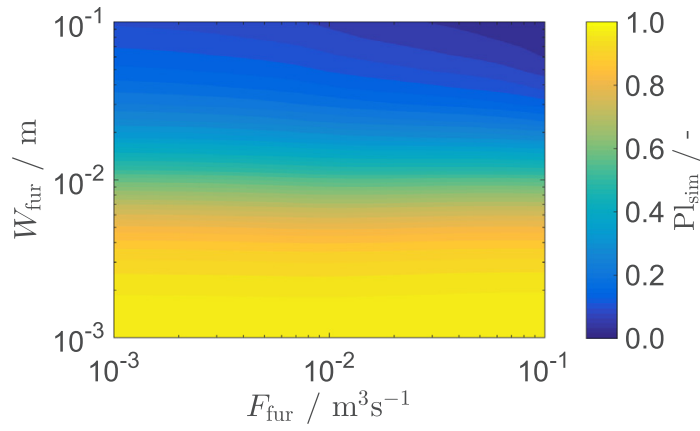

Fig. 12. Relevance of conductive heat transfer ranging from zero $(0 \%)$ to unity $(100 \%)$ versus the furnace side width illustrated with the Planck number from simulations $\mathrm{Pl}_{\text {sim }}$ for any simulation of the autothermal channel reactor.

- are favorable.

\subsubsection{Furnace inlet temperature and flue gas volume flow}

The remaining operating parameter $-T_{\text {fur }}^{(\text {in) }}-$ is analyzed in Fig. 13 for both reformer side designs $D_{1}$ and $D_{2}$. $Y_{C O}$ is shown on the left (Fig. 13A and C) whereas $S T Y_{\mathrm{CO}}$ is shown on the right hand side (Fig. 13B and D). All results are for $S / C=1 / 1$ but the results can be generalized for other $S / C$ ratios. Flue gas temperatures are analyzed in the range $1000 \mathrm{~K} \leqslant T_{\text {fur }}^{\text {(in) }} \leqslant 2000 \mathrm{~K}$ in order to include the possibility of using exhaust flue gases at the lower end of the temperature scale to provide the energy for the reforming side. The maximum temperature corresponds to the combustion temperature of $\mathrm{CH}_{4}$. Higher temperatures could nonetheless be achieved with oxygen-enriched combustion. Maximum yields close to unity and space time yields at $550 \mathrm{~mol} \mathrm{~m}^{-3} \mathrm{~s}^{-1}$ are attainable for $\mathrm{D}_{1}$ and are highlighted with the dotted line and region I. The situation is different for design $\mathrm{D}_{2}$ : the maximum yield is not attainable even at maximum furnace inlet temperature and furnace volume flow. Consequently, $S T Y_{\mathrm{CO}}$ is continuously increasing with $T_{\text {fur }}^{\text {(in) }}$ and $F_{\text {fur }}$. Despite its lower attainable yield, $\mathrm{D}_{2}$ attains much higher $S T Y_{\mathrm{CO}}$ values up to $1630 \mathrm{~mol} \mathrm{~m}^{-3} \mathrm{~s}^{-1}$ thus increasing the catalyst productivity by factor of three compared to $\mathrm{D}_{1}$. One optimal result per reforming side design and per feed composition is selected and all results are compared in Table 2. Regarding the efficiency per furnace gas flow that was defined above, maximum furnace inlet
Table 2

Summary for design $\mathrm{D}_{1}$ and $\mathrm{D}_{2}$ : reforming side design and operating parameters in the top section for maximizing $Y_{\mathrm{CO}} S T Y_{\mathrm{CO}}$ at high and low $S / C$ ratios, furnace side parameters and all performance indicators $Y_{\mathrm{CO}}, \widehat{Y}_{\mathrm{CO}}, S T Y_{\mathrm{CO}}$ and $S \widehat{T} Y_{\mathrm{CO}}$ at the bottom.

\begin{tabular}{|c|c|c|c|c|c|}
\hline & & \multicolumn{2}{|c|}{ Design $D_{1}$} & \multicolumn{2}{|c|}{ Design $D_{2}$} \\
\hline & & $\max Y_{\mathrm{CO}}$ & $\max \widehat{Y}_{\mathrm{CO}}$ & $\max Y_{\mathrm{CO}}$ & $\max \widehat{Y}_{\mathrm{CO}}$ \\
\hline$L$ & $\mathrm{~m}$ & & .5 & \\
\hline$W_{\text {ref }}$ & $\mathrm{m}$ & & & \multicolumn{2}{|c|}{$4.28 \times 10^{-3}$} \\
\hline$F_{\text {ref }}$ & $\mathrm{m}^{3} \mathrm{~s}^{-1}$ & \multicolumn{2}{|c|}{$9.14 \times 10^{-4}$} & \multicolumn{2}{|c|}{$3.51 \times 10^{-3}$} \\
\hline$S / C$ & - & $1 / 1$ & $3 / 1$ & $1 / 1$ & $3 / 1$ \\
\hline$W_{\text {fur }}$ & $\mathrm{m}$ & \multicolumn{4}{|c|}{$W_{\text {fur }} \leqslant 4 \mathrm{~mm}$ or $20 \mathrm{~mm} \leqslant W_{\text {fur }}$} \\
\hline$F_{\text {fur }}$ & $\mathrm{m}^{3} \mathrm{~s}^{-1}$ & $2.98 \times 10^{-2}$ & $8.86 \times 10^{-3}$ & $1.00 \times 10^{-1}$ & $1.83 \times 10^{-2}$ \\
\hline$T_{\text {fur }}^{\text {(in) }}$ & $\mathrm{K}$ & 2000 & 2000 & 2000 & 2000 \\
\hline$Y_{\mathrm{CO}}$ & $\%$ & 98 & 55 & 79 & 31 \\
\hline$\widehat{Y}_{\mathrm{CO}}$ & $\mathrm{m}^{-3} \mathrm{~s}$ & 33 & 62 & 8 & 17 \\
\hline$S T Y_{\mathrm{CO}}$ & $\mathrm{mol} \mathrm{m}^{-3} \mathrm{~s}^{-1}$ & 553 & 155 & 1712 & 333 \\
\hline$S \widehat{T T} Y_{\mathrm{CO}}$ & $\mathrm{mol} \mathrm{m}^{-6}$ & $1.86 \times 10^{4}$ & $1.75 \times 10^{4}$ & $1.71 \times 10^{4}$ & $1.82 \times 10^{4}$ \\
\hline
\end{tabular}

temperature and flow rates in the range $F_{\text {fur }}=6.0 \times 10^{-3}-2.00 \times 10^{-2} \mathrm{~m}^{3} \mathrm{~s}^{-1}$ define the optimal operating region because gradients of $Y_{\mathrm{CO}}$ and $S T Y_{\mathrm{CO}}$ with respect to increasing $F_{\text {fur }}$ are highest with these operating parameters for all designs and reforming operating parameters considered. The scenarios in Table 2 are thus selected in this furnace operating region in order to maximize $Y_{\mathrm{CO}}, S T Y_{\mathrm{CO}}$ as well as $\widehat{Y}_{\mathrm{CO}}$ and $S \widehat{T} Y_{\mathrm{CO}}$. While both designs $\mathrm{D}_{1}$ and $\mathrm{D}_{2}$ attain similar values for $S \widehat{T} Y_{\mathrm{CO}}, \mathrm{D}_{1}$ outperforms $\mathrm{D}_{2}$ in terms of $\widehat{Y}_{\mathrm{CO}}$ by a factor of three to four. In total, product yield $Y_{\mathrm{CO}}$ as well as fuel usage per yield of the microchannel design $\mathrm{D}_{1}$ are higher than for the wider channel in design $\mathrm{D}_{2}$ but other than reported in literature the catalyst productivity $S T Y_{\mathrm{CO}}$ of design $\mathrm{D}_{2}$ is by a factor of two to three higher than for $\mathrm{D}_{1}$ at an equal $S T Y_{\mathrm{CO}}$ per fuel ratio for both maximum product yield and fuel usage per yield [40]. This insight is possible due to the usage of the detailed radiation model indicating that radiative heat transfer accounts for approximately $20 \%$ in design $\mathrm{D}_{2}$. In practice, additional contributing factors such as coke formation are relevant for the selection of the minimum ratio of $S / C$ that is feasible.
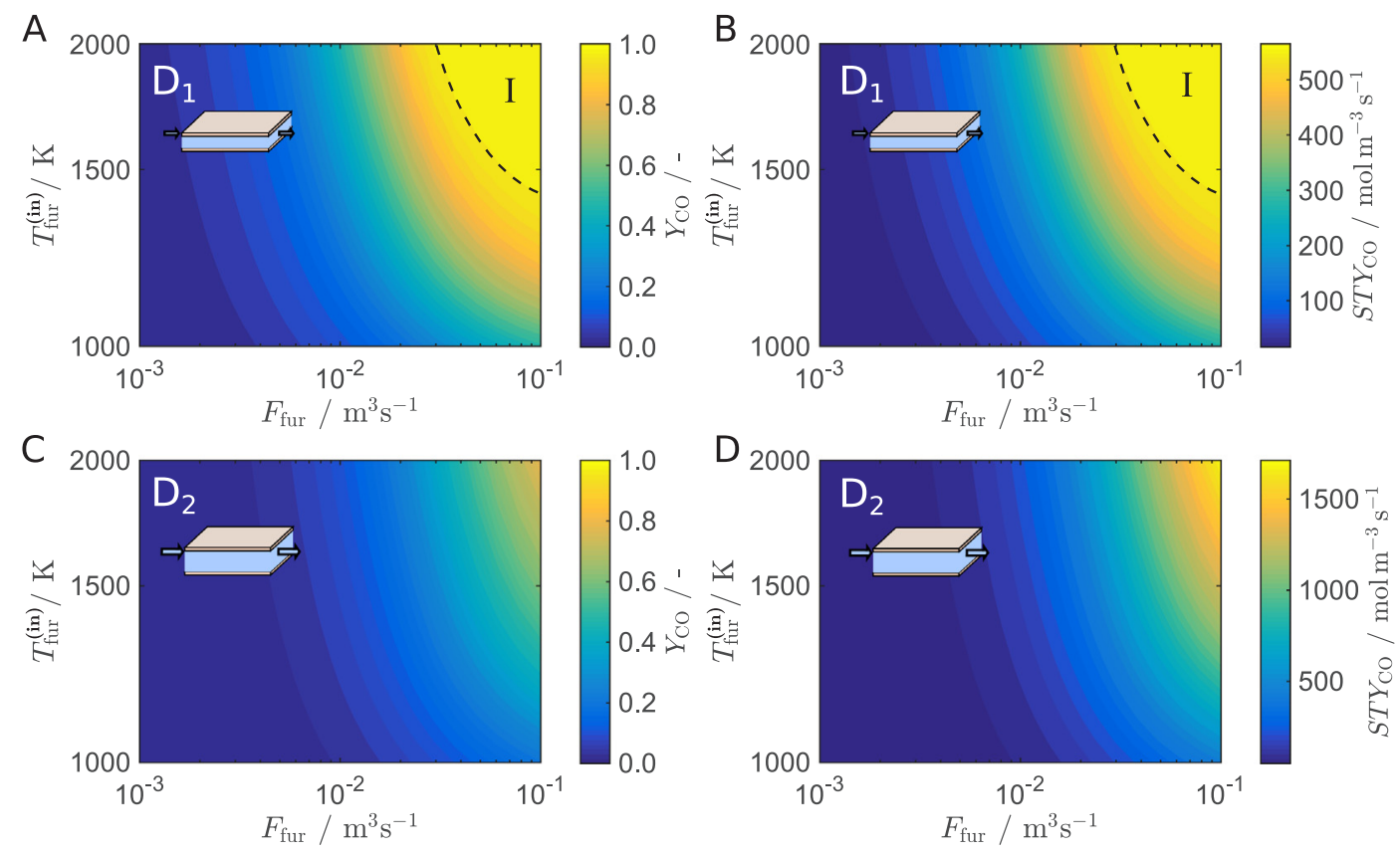

Fig. 13. $Y_{C O}$ for reforming designs $\mathrm{D}_{1}(\mathrm{~A})$ and $\mathrm{D}_{2}(\mathrm{C})$ as well as $S T Y_{C O}$ for both designs (C and $\left.\mathrm{D}\right)$ at $S / C=1 / 1$. 


\section{Conclusion}

In summary, a two-dimensional steady channel reactor model is presented and validated for the case study of autothermal methane steam reforming with adjacent reforming and furnace compartments. The model validation is adequate but comparison of the three relevant reaction kinetic models with more thorough experimental data is desirable in the future. The importance of the radiation model is highlighted for a study of reactor width because radiative heat transfer becomes equally important or even dominates overall heat transfer for widths above $5 \mathrm{~mm}$. Three design $-L, W_{\text {ref }}, W_{\text {fur }}-$ and four operating parameters $-F_{\text {ref }}, S / C, F_{\text {fur }}$ and $T_{\text {fur }}^{(\text {in) }}-$ are identified as target design constraints for a constant catalyst volume $V_{\text {cat }}$ and analyzed in two consecutive design studies: In a first step, the reforming side parameters are studied and it is shown that maxima of $Y_{\mathrm{CO}}$ and $S T Y_{\mathrm{CO}}$ are not achieved with a single design and both objectives thus have to be balanced: two promising candidates one for maximum $Y_{\mathrm{CO}}$ and low $S T Y_{\mathrm{CO}}$ $\left(\mathrm{D}_{1}\right)$ and one for intermediate $Y_{\mathrm{CO}}$ and $S T Y_{\mathrm{CO}}\left(\mathrm{D}_{2}\right)$ are selected for a study in the coupled reforming-furnace model in the second step. Furnace width $W_{\text {fur }}$ is of secondary importance if no chemical reaction is studied on the furnace side but it is shown that furnace widths below $4 \mathrm{~mm}$ and above $20 \mathrm{~mm}$ are favorable. Maximum yields $Y_{\mathrm{CO}}$ close to thermodynamic equilibrium are attained for designs $D_{1}$ but not for designs $\mathrm{D}_{2}$ even at maximum furnace inlet temperature and furnace gas volume flow. Additionally, designs $\mathrm{D}_{1}$ have better performance than designs $D_{2}$ in terms of yield per fuel. Both designs $D_{1}$ and $D_{2}$ are equivalent with respect to attainable fuel efficiency $S \widehat{T} Y_{\mathrm{CO}}$. Despite its lower product purity, designs $D_{2}$ outperform designs $D_{1}$ in their catalyst productivities $S T Y_{\mathrm{CO}}$ by a factor of two to three depending on the reforming side feed $S / C$ ratio while achieving still a moderate product purity. Radiative heat transfer is negligible for the reforming side of designs $\mathrm{D}_{1}$ but accounts for $20 \%$ on the reforming side of designs $\mathrm{D}_{2}$.

To conclude, it was shown that balancing product purity, fuel efficiency and catalyst efficiency is required in each given scenario is necessary. The microchannel design $\mathrm{D}_{1}$ performs better for the first two aspects but has disadvantages wherever high catalyst productivity is required e.g. if the limiting factor is a more active catalysts than Ni such as expensive noble metals. Therefore, the monolith design which is frequently used as a benchmark in reactor design due to its low heat and mass transport barriers must be scrutinized carefully for a real design besides all additional challenges for larger-scale applications. An overall best design can therefore not be selected because of the conflicting objectives and thus context dependency of the optimality of a solution. This requires further studies that take into account the overall process or even plant perspective.

\section{Acknowledgements}

The author Georg Liesche is also affiliated to the International Max Planck Research School (IMPRS) for Advanced Methods in Process Systems Engineering (Magdeburg).

\section{References}

[1] M. Wackernagel, S. Browne, Earth overshoot day,https://www.overshootday.org/, 2018. (accessed 08.06.2018, last modified: 07.07.2018).

[2] D. Bosseboeuf, Energy efficiency trends and policies in industry - an analysis based on the ODYSSEE and MURE databases.http://www.odyssee-mure.eu/publications/ br/energy-efficiency-in-industry.html, 2015 (accessed 08.06.2018, last modified: 06.06.2018).

[3] N. Zhang, R. Smith, I. Bulatov, J.J. Klemeš, Sustaining high energy efficiency in existing processes with advanced process integration technology, Appl. Energy 101 (2013) 26-32.

[4] A.M. Bazzanella, F. Ausfelder, Low carbon energy and feedstock for the European chemical industry, Technology Study, Frankfurt a.M, 2017.

[5] R. Reimert, F. Marschner, H.-J. Renner, W. Boll, E. Supp, M. Brejc, W. Liebner, Gas production, 2. Processes, in: Ullmann's Encyclopedia of Industrial Chemistry, WileyVCH Verlag GmbH \& Co. KGaA, Weinheim, Germany, 2000, pp. 423-482.

[6] J.R. Rostrup-Nielsen, Production of synthesis gas, Catal. Today 18 (1993) 305-324.
[7] I. Dybkjaer, Tubular reforming and autothermal reforming of natural gas - an overview of available processes, Fuel Process. Technol. 42 (1995) 85-107.

[8] A. Kumar, T.F. Edgar, M. Baldea, Multi-resolution model of an industrial hydrogen plant for plantwide operational optimization with non-uniform steam-methane reformer temperature field, Comput. Chem. Eng. 107 (2017) 271-283.

[9] J.D. Medrano-García, R. Ruiz-Femenia, J.A. Caballero, Multi-objective optimization of combined synthesis gas reforming technologies, J. $\mathrm{CO}_{2}$ Utiliz. 22 (2017) $355-373$.

[10] A. Tran, A. Aguirre, H. Durand, M. Crose, P.D. Christofides, Cfd modeling of a industrial-scale steam methane reforming furnace, Chem. Eng. Sci. 171 (2017) 576-598.

[11] A. Tran, A. Aguirre, M. Crose, H. Durand, P.D. Christofides, Temperature balancing in steam methane reforming furnace via an integrated cfd/data-based optimization approach, Comput. Chem. Eng. 104 (2017) 185-200.

[12] D.A. Latham, K.B. McAuley, B.A. Peppley, T.M. Raybold, Mathematical modeling of an industrial steam-methane reformer for on-line deployment, Fuel Process. Technol. 92 (2011) 1574-1586.

[13] A. Olivieri, F. Vegliò, Process simulation of natural gas steam reforming: fuel distribution optimisation in the furnace, Fuel Process. Technol. 89 (2008) 622-632.

[14] J.K. Rajesh, S.K. Gupta, G.P. Rangaiah, A.K. Ray, Multiobjective optimization of steam reformer performance using genetic algorithm, Ind. Eng. Chem. Res. 39 (2000) 706-717.

[15] Andrew E. Lutz, Robert W. Bradshaw, Jay O. Keller, Dennis E. Witmer, Thermodynamic analysis of hydrogen production by steam reforming, Int. J. Hydrogen Energy 28 (2003) 159-167.

[16] J. Piña, N.S. Schbib, V. Bucalá, D.O. Borio, Influence of the heat-flux profiles on the operation of primary steam reformers, Ind. Eng. Chem. Res. 40 (2001) 5215-5221.

[17] A. Z'Graggen, A. Steinfeld, Hydrogen production by steam-gasification of carbonaceous materials using concentrated solar energy - v. Reactor modeling, optimization, and scale-up, Int. J. Hydrogen Energy 33 (2008) 5484-5492.

[18] M.A. Murmura, S. Cerbelli, M.C. Annesini, Modelling and optimization of hydrogen yield in membrane steam reforming reactors, Can. J. Chem. Eng. 95 (2017) 1676-1682.

[19] D.L. Hoang, S.H. Chan, Modeling of a catalytic autothermal methane reformer for fuel cell applications, Appl. Catal. A: General 268 (2004) 207-216.

[20] J. Frauhammer, G. Eigenberger, L.V. Hippel, D. Arntz, A new reactor concept for endothermic high-temperature reactions, Chem. Eng. Sci. 54 (1999) 3661-3670.

[21] H. Butcher, C.J. Quenzel, L. Breziner, J. Mettes, B.A. Wilhite, P. Bossard, Design of an annular microchannel reactor (amr) for hydrogen and/or syngas production via methane steam reforming, Int. J. Hydrogen Energy 39 (2014) 18046-18057.

[22] A.Y. Tonkovich, S. Perry, Y. Wang, D. Qiu, T. LaPlante, W.A. Rogers, Microchannel process technology for compact methane steam reforming, Chem. Eng. Sci. 59 (2004) 4819-4824.

[23] A. Fazeli, M. Behnam, Cfd modeling of methane autothermal reforming in a catalytic microreactor, Int. J. Chem. Reactor Eng. 5 (2007) 1-14.

[24] Y.-X. Huang, J.-Y. Jang, C.-H. Cheng, Fractal channel design in a micro methanol steam reformer, Int. J. Hydrogen Energy 39 (2014) 1998-2007.

[25] M.H. Akbari, A.S. Ardakani, M.A. Tadbir, A microreactor modeling, analysis and optimization for methane autothermal reforming in fuel cell applications, Chem. Eng. J. 166 (2011) 1116-1125.

[26] A.K. Chaniotis, D. Poulikakos, Modeling and optimization of catalytic partial oxidation methane reforming for fuel cells, J. Power Sour. 142 (2005) 184-193.

[27] M.A. Murmura, M. Diana, R. Spera, M.C. Annesini, Modeling of autothermal methane steam reforming: comparison of reactor configurations, Chem. Eng. Process. 109 (2016) 125-135.

[28] H. Freund, K. Sundmacher, Towards a methodology for the systematic analysis and design of efficient chemical processes: part 1 - from unit operations to elementary process functions, Chem. Eng. Process. 47 (2008) 2051-2060.

[29] N.M. Kaiser, R.J. Flassig, K. Sundmacher, Reactor-network synthesis via flux profile analysis, Chem. Eng. J. 335 (2018) 1018-1030.

[30] E.C. Wanat, K. Venkataraman, L.D. Schmidt, Steam reforming and water-gas shift of ethanol on rh and rh-ce catalysts in a catalytic wall reactor, Appl. Catal. A: General 276 (2004) 155-162.

[31] K. Venkataraman, E.C. Wanat, L.D. Schmidt, Steam reforming of methane and water-gas shift in catalytic wall reactors, AIChE J. 49 (2003) 1277-1284.

[32] A. Ricca, V. Palma, M. Martino, E. Meloni, Innovative catalyst design for methane steam reforming intensification, Fuel 198 (2017) 175-182.

[33] J. Xu, G.F. Froment, Methane steam reforming: Ii. Diffusional limitations and reactor simulation, AIChE J. 35 (1989) 97-103.

[34] M. Irani, A. Alizadehdakhel, A.N. Pour, N. Hoseini, M. Adinehnia, Cfd modeling of hydrogen production using steam reforming of methane in monolith reactors: surface or volume-base reaction model? Int. J. Hydrogen Energy 36 (2011) 15602-15610.

[35] D. Wolf, M. Höhenberger, M. Baerns, External mass and heat transfer limitations of the partial oxidation of methane over a $\mathrm{Pt} / \mathrm{MgO}$ catalystconsequences for adiabatic reactor operation, Ind. Eng. Chem. Res. 36 (1997) 3345-3353.

[36] G. Kolios, J. Frauhammer, G. Eigenberger, A simplified procedure for the optimal design of autothermal reactors for endothermic high-temperature reactions, Chem. Eng. Sci. 56 (2001) 351-357.

[37] G. Kolios, J. Frauhammer, G. Eigenberger, Efficient reactor concepts for coupling of endothermic and exothermic reactions, Chem. Eng. Sci. 57 (2002) 1505-1510.

[38] M. Mundhwa, R.D. Parmar, C.P. Thurgood, A comparative parametric study of a catalytic plate methane reformer coated with segmented and continuous layers of combustion catalyst for hydrogen production, J. Power Sour. 344 (2017) 85-102.

[39] G. Arzamendi, P.M. Diéguez, M. Montes, J.A. Odriozola, E.F. Sousa-Aguiar, L.M. Gandía, Methane steam reforming in a microchannel reactor for gtl 
intensification: a computational fluid dynamics simulation study, Chem. Eng. J. 154 (2009) 168-173.

[40] A. Karim, J. Bravo, D. Gorm, T. Conant, A. Datye, Comparison of wall-coated and packed-bed reactors for steam reforming of methanol, Catal. Today 110 (2005) 86-91.

[41] X. Zhai, S. Ding, Y. Cheng, Y. Jin, Y. Cheng, Cfd simulation with detailed chemistry of steam reforming of methane for hydrogen production in an integrated microreactor, Int. J. Hydrogen Energy 35 (2010) 5383-5392.

[42] M.J. Stutz, N. Hotz, D. Poulikakos, Optimization of methane reforming in a microreactor-effects of catalyst loading and geometry, Chem. Eng. Sci. 61 (2006) 4027-4040.

[43] E. Krause, H. Schlichting, H.J. Oertel, K. Gersten, Grenzschicht-Theorie, 10th ed., Springer, Berlin Heidelberg, 2013.

[44] D.R. Burgess, Thermochemical data, in: NIST Chemistry WebBook: NIST Standard Reference Database Number 69, Gaithersburg MD, 20899, 2017.

[45] R.B. Bird, W.E. Stewart, E.N. Lightfoot, Transport Phenomena, Wiley International Edition, Wiley, 2007.

[46] M. Jischa, Konvektiver Impuls-, Wärme- und Stoffaustausch, Grundlagen und Fortschritte der Ingenieurwissenschaften, Vieweg + Teubner Verlag, 1982.

[47] C.R. Wilke, A viscosity equation for gas mixtures, J. Chem. Phys. 18 (1950) 517.

[48] R.J. Kee, G. Dixon-Lewis, J. Warnatz, M.E. Coltrin, J.A. Miller, A fortran computer code package for the evaluation of gas-phase, multicomponent transport properties, SAND86-8246, 1986.

[49] E.N. Fuller, P.D. Schettler, J.C. Giddings, A new method for prediction of binary gas phase diffusion coefficients, Ind. Eng. Chem. 58 (1966) 19-27.

[50] J. Andersson, A general-purpose software framework for dynamic optimization (Ph. D. thesis), Arenberg Doctoral School, KU Leuven, Department of Electrical Engineering (ESAT/SCD) and Optimization in Engineering Center, Kasteelpark Arenberg 10, 3001-Heverlee, Belgium, 2013.

[51] A.C. Hindmarsh, P.N. Brown, K.E. Grant, S.L. Lee, R. Serban, D.E. Shumaker, C.S. Woodward, Sundials: suite of nonlinear and differential/algebraic equation solvers, ACM Trans. Math. Software 31 (2005) 363-396.

[52] S. Patankar, Numerical Heat Transfer and Fluid Flow, Series in Computational Methods in Mechanics and Thermal Sciences, Taylor \& Francis, 1980.

[53] F. Graziani, Computational Methods in Transport: Verification and Validation, Lecture Notes in Computational Science and Engineering, Springer, Berlin Heidelberg, 2008.

[54] J. Bremer, Karsten H.G. Rätze, K. Sundmacher, $\mathrm{CO}_{2}$ methanation: Optimal start-up control of a fixed-bed reactor for power-to-gas applications, AIChE J. 63 (2017) 23-31.

[55] G. Kolios, A. Gritsch, B. Glöckler, G. Sorescu, J. Frauhammer, Novel reactor concepts for thermally efficient methane steam reforming: modeling and simulation, Indus. Eng. Chem. Res. 43 (2004) 4796-4808.

[56] M.F. Modest, Radiative Heat Transfer, Academic Press, 2013.

[57] R.V. Kochanov, I.E. Gordon, L.S. Rothman, P. Wcisło, C. Hill, J.S. Wilzewski, Hitran application programming interface (hapi): a comprehensive approach to working with spectroscopic data, J. Quantitative Spectrosc. Radiative Transfer 177 (2016) $15-30$.
[58] H. Zhang, M.F. Modest, Evaluation of the planck-mean absorption coefficients from hitran and hitemp databases, J. Quantitative Spectrosc. Radiative Transfer 73 (2002) 649-653.

[59] L.S. Rothman, I.E. Gordon, R.J. Barber, H. Dothe, R.R. Gamache, A. Goldman, V.I. Perevalov, S.A. Tashkun, J. Tennyson, Hitemp, the high-temperature molecular spectroscopic database, J. Quantitative Spectrosc. Radiative Transfer 111 (2010) 2139-2150.

[60] L.S. Rothman, I.E. Gordon, Y. Babikov, A. Barbe, D. Chris Benner, P.F. Bernath, M. Birk, L. Bizzocchi, V. Boudon, L.R. Brown, A. Campargue, K. Chance, E.A. Cohen, L.H. Coudert, V.M. Devi, B.J. Drouin, A. Fayt, J.-M. Flaud, R.R. Gamache, J.J. Harrison, J.-M. Hartmann, C. Hill, J.T. Hodges, D. Jacquemart, A. Jolly, J. Lamouroux, R.J. Le Roy, G. Li, D.A. Long, O.M. Lyulin, C.J. Mackie, S.T. Massie, S. Mikhailenko, H. Müller, O.V. Naumenko, A.V. Nikitin, J. Orphal, V. Perevalov, A. Perrin, E.R. Polovtseva, C. Richard, M. Smith, E. Starikova, K. Sung, S. Tashkun, J. Tennyson, G.C. Toon, V. Tyuterev, G. Wagner, The hitran2012 molecular spectroscopic database, J. Quantitative Spectrosc. Radiative Transfer 130 (2013) 4-50.

[61] H. Chu, M. Gu, H. Zhou, F. Liu, Calculations of narrow-band transimissities and the planck mean absorption coefficients of real gases using line-by-line and statistical narrow-band models, Front. Energy 8 (2014) 41-48.

[62] J.R. Howell, M.P. Menguc, R. Siegel, Thermal Radiation Heat Transfer, fifth ed., CRC Press, 2010.

[63] C.E. Baukal, Heat Transfer in Industrial Combustion, Industrial Combustion, CRC Press, 2000.

[64] J. Xu, G.F. Froment, Methane steam reforming, methanation and water-gas shift: I. Intrinsic kinetics, AIChE J. 35 (1989) 88-96.

[65] J. Wei, E. Iglesia, Mechanism and site requirements for activation and chemical conversion of methane on supported pt clusters and turnover rate comparisons among noble metals, J. Phys. Chem. B 108 (2004) 4094-4103.

[66] M. Zeppieri, P.L. Villa, N. Verdone, M. Scarsella, P.d. Filippis, Kinetic of methane steam reforming reaction over nickel- and rhodium-based catalysts, Appl. Catal. A: General 387 (2010) 147-154.

[67] B.T. Schädel, M. Duisberg, O. Deutschmann, Steam reforming of methane, ethane, propane, butane, and natural gas over a rhodium-based catalyst, Catal. Today 142 (2009) 42-51.

[68] L.I. Maier, B. Schädel, K. Herrera Delgado, S. Tischer, O. Deutschmann, Steam reforming of methane over nickel: development of a multi-step surface reaction mechanism, Top. Catal. 54 (2011) 845-858.

[69] M. Karakaya, S. Keskin, A.K. Avci, Parametric study of methane steam reforming to syngas in a catalytic microchannel reactor, Appl. Catal. A: General 411-412 (2012) $114-122$.

[70] O. Levenspiel, Chemical Reaction Engineering, Wiley, 1999.

[71] S. Kodama, K. Fukui, A. Mazume, Relation of space velocity and space time yield, Ind. Eng. Chem. 45 (1953) 1644-1648.

[72] R. Reimert, C. Higman, W. Hilsebein, V. Gronemann, U. Zwiefelhofer, Albrecht J., Gas production, 5. Examples of complex gas production plants, in: Ullmann's Encyclopedia of Industrial Chemistry, volume, vol. 16, Wiley-VCH Verlag GmbH \& Co. KGaA, Weinheim, Germany, 2000, pp. 557-570. 